Portland State University

PDXScholar

\title{
Towards a measure of superior-subordinate perceptual correspondence and its relationship to the performance appraisal
}

Elizabeth Duane Vergeer Crist

Portland State University

Follow this and additional works at: https://pdxscholar.library.pdx.edu/open_access_etds

Part of the Cognition and Perception Commons, and the Speech Pathology and Audiology Commons Let us know how access to this document benefits you.

\section{Recommended Citation}

Crist, Elizabeth Duane Vergeer, "Towards a measure of superior-subordinate perceptual correspondence and its relationship to the performance appraisal" (1982). Dissertations and Theses. Paper 3189. https://doi.org/10.15760/etd.3180

This Thesis is brought to you for free and open access. It has been accepted for inclusion in Dissertations and Theses by an authorized administrator of PDXScholar. Please contact us if we can make this document more accessible: pdxscholar@pdx.edu. 
AN ABSTRACT OF THE THESIS OF Elizabeth Duane Vergeer Crist for the Master of Science in Speech Communication presented November 15, 1982 .

Title: Toward a Measure of Superior-Subordinate Perceptual Correspondence and its Relationship to the Performance Appraisal.

APPROVED BY MEMBERS OF THE THESIS COMMITTEE:

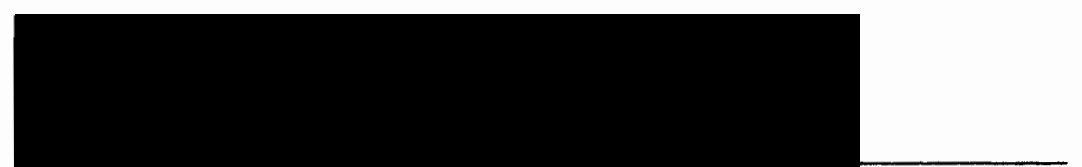

Frank/Roberts, Chairman

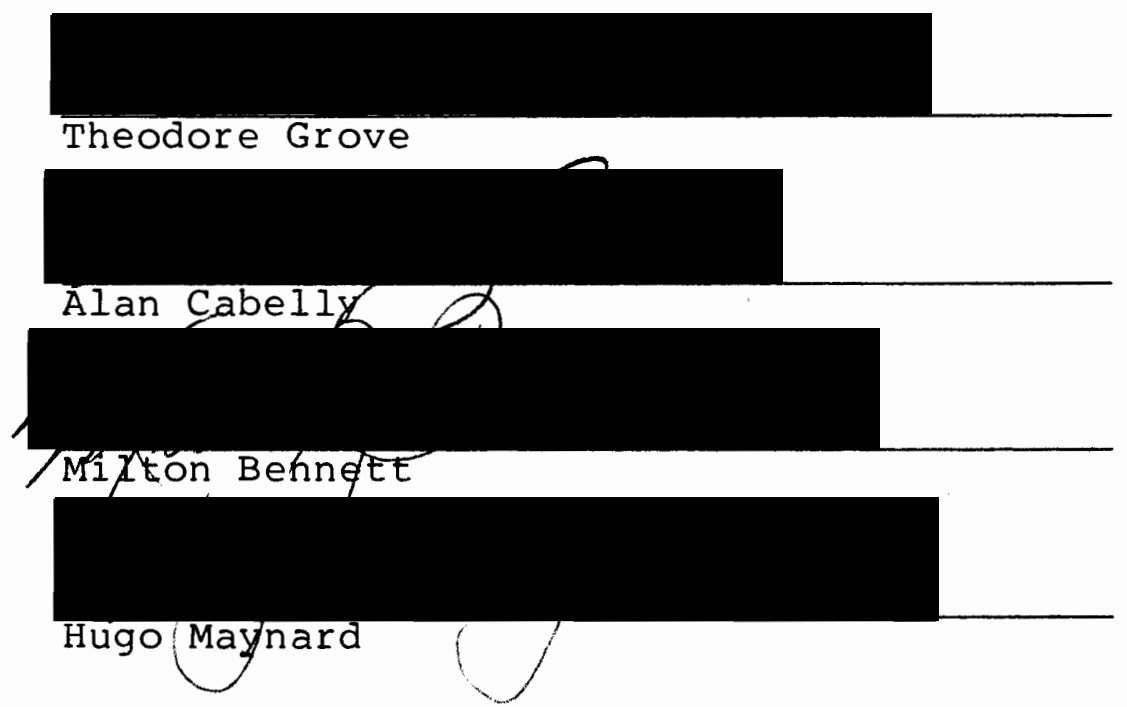

The purpose of the present study was to determine what, if any, relationship existed between the correspondence of perceptions between superior-subordinate work dyads and the superior's rating of the subordinate's work performance. 
In order to assess the perceptual aspect of interpersonal communication, an instrument was developed to measure individual perceptions, which were subsequently compared for measures of agreement/disagreement, understanding/ misunderstanding, realization/lack of realization, and feelings of being understood/misunderstood. Development of the Superior-Subordinate Interpersonal Perception Method (SSIPM) involved identification of issues germane to the work relationship through several phases. The pilot form of the SSIPM included 40 items and was implemented using a test-retest method with eleven superior-subordinate subject pairs. Resulting data was analyzed for reliability on the basis of test-retest correlation coefficients and itemtotal correlation coefficients. Thus, the 16 most reliable items were identified for inclusion on the final form of the SSIPM. The final study involved 52 superior-subordinate work dyads from 11 different organizations. All participants responded to the SSIPM; superiors rated their subordinate using a general performance appraisal instrument. Data analysis from SSIPM scores (total matching perceptions across all issues and perceptual levels) and performance appraisal scores resulted in a direct and significant relationship.

The development of the SSIPM represents an effort to measure the correspondence of dyadic perceptions; the final study represents an effort to learn how those superiorsubordinate perceptions relate to the performance appraisal. 
A moderately high Cronbach's Alpha was produced by the reliability analysis, suggesting that the instrument has merit. The significant positive relationship established between the SSIPM and the performance appraisal indicates support for the theory that perceptions between co-workers are related to how one judges the performance of the other. 
TOWARDS A MEASURE OF SUPERIOR-SUBORDINATE PERCEPTUAL CORRESPONDENCE AND ITS RELATIONSHIP TO THE PERFORMANCE APPRAISAL

by

ELIZABETH DUANE VERGEER CRIST

A thesis submitted in partial fulfillment of the requirements for the degree of

\author{
MASTER OF SCIENCE \\ in \\ SPEECH COMMUNICATION
}

Portland State University

1982 
TO THE OFFICE OF GRADUATE STUDIES AND RESEARCH:

The members of the committee approve the thesis of

Elizabeth Duane Vergeer Crist presented November 15, 1982.

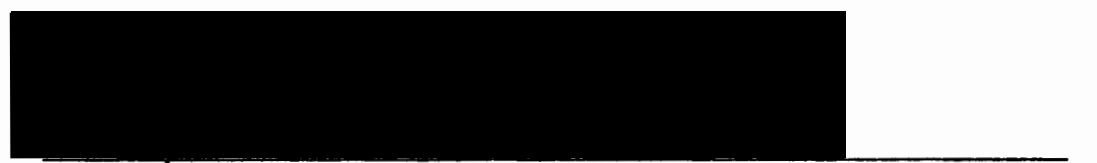

Frank Roberts, Chairman

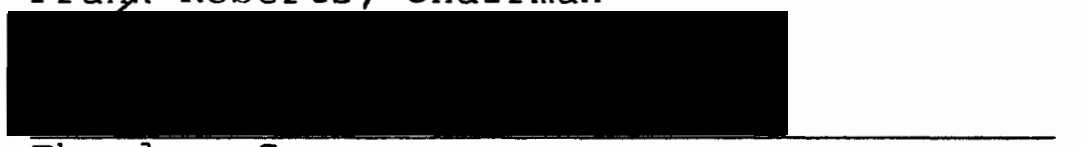

Theodore Grove

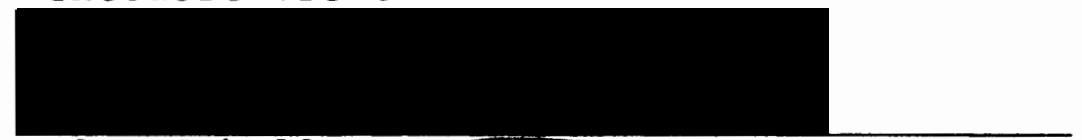

Alan Cabelly

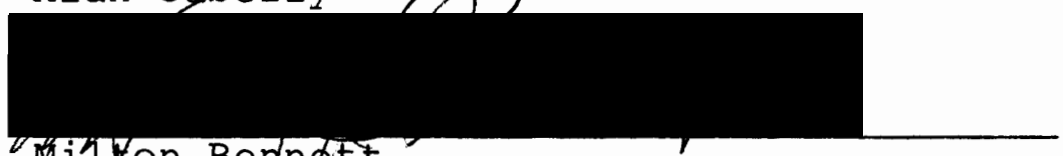

Milzon Bennett

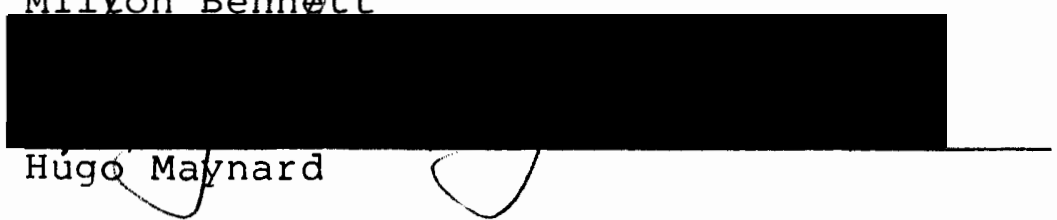

APPROVED :

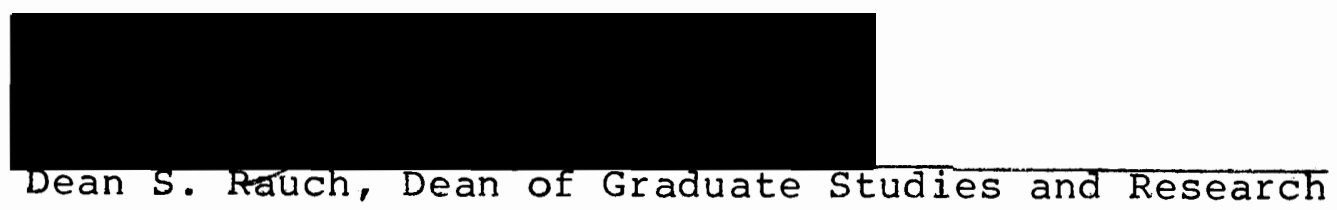




\section{ACKNOWLEDGEMENTS}

I acknowledge all my committee members and the office of Graduate Studies and Research representative for their willingness to read and review this research. I appreciate Dr. Frank Roberts for serving as my advisor and committee chairman. We will, hopefully, "graduate" together from Portland State University.

There are several people to whom I feel gratitude as I complete this study. It's the people, as well as the ideas, that have made this study meaningful to me.

Dr. Theodore Grove is where this project began and ended. In the beginning, he introduced the ideas of R.D. Laing and the IPM to me; in the end, he was the sage who knew how to talk to the computer. Eight years ago, after my first class with him, I described him to my husband as an "idea-a-minute-man"; I could not do better now. His knowledge and good humor have served to make this study possible.

Dr. Alan Cabelly is especially appreciated for his commitment, ability and performance as an instructor and thesis advisor. Although consistently busy, he never failed to listen, question, instruct and generally make himself available to me throughout this lengthy process. Faltering, as one does when learning and going through a 
complex process for the first time, I was never made to feel "less than." His encouragement was present throughout.

My friend, Deborah Coker, served to inspire and encourage me as I saw her successfully implement her study and complete her thesis. It is great comfort to know someone "in the same boat." I feel fortunate to have been in the same place at the same time.

My parents, Marjorie and Duane Vergeer, are the people who forever model the traits and behavior I strive for. They are caring, hard working, always interested in, and an active part of, the world around them. They have confidence in me.

My son, Brian, helped return me to this master's program when, after one of my lectures about the importance of goals in one's life, he asked me about mine.

My son, David, helped me complete my writing by his awareness of the demands on my time. He noticed what needed doing around the house, and did it.

My husband, Rich, is the person upon whom I can always rely. He consistently provides emotional and financial support. He always listens, and asks the right questions, clarifying issues and helping to set them into perspective. He consistently loves me, and has faith in my ability. With that kind of support, anything is possible. 
TABLE OF CONTENTS

PAGE

ACKNOWL ED GEMENTS

LIST OF TABLES

viii

LIST OF FIGURES

ix

CHAPTER

I INTRODUCTION. . . . . . . . . .

II THEORET ICAL FRAMEWORK • • • • • • •

Person Perception : $\cdot \cdot \cdot \cdot \cdot \cdot \cdot$

Interpersonal Relationships. . .

Dyadic Relationships at Work . .

Performance Appraisal Theory . .

Summary. •. • . . . . . .

III PERCEPTUAL MEASUREMENT • . • . • •

The Interpersonal Perception

Method (IPM)...........

Survey of Personnel Professionals

Issue Category Survey of Academic Experts. • . • • • • • • •

Construction of Format Statements

As sembly of the Pilot Test . . .

Test Response Method \& Meaning. .

Overview ............

Pilot Study. . . . . . . . . . .

Human Subjects Research Review.

Subjects . . . . . . . . .

Procedures . . . . . . . . .

Data Analysis and Test Item

Reliability Study : . . . . .

Item Analysis. . . . . . . . 
Page

Hypothesis . . . . . . . 48

Description: Performance Appraisal 48

Operational Definitions. . . . 49

Subjects . . . . . . . . . 52

Procedures . . • . . . . . $\quad 53$

VII RESUITS - • • - • • • • • • • • 56

Reliability of the SSIPM. . . $\quad 56$

Test of Hypothesis. . . . . $\quad 56$

The Global Interpretation . . 59

The Role Interpretation . . . 59

Response Level Interpretation . 60

Issue Category Interpretation. 61

Issue Interpretation. ..... 61

VIII DISCUSSION - . . . - . . . . . 67

IX IIMITATIONS AND RECOMMENDATIONS. • • 72

Issue Category Survey of

Academic Experts . . . . 72

Test Reliability. • . . . . . 72

Performance Appraisal . . . . 72

Sampling Technique. . . . . 73

Methods and Procedures. . . . 74

X CONCLUSION • • • • • • • • • • • 75

REFERENCES • • • • • • • • • • •

APPENDICES • • • • • • . . • • •

Appendix A - Test Issue

Candidates . . . . . . . . 84

Appendix B - Letter to Person-

nel Professionals. . . . 89

Appendix C - Survey of Personnel Professionals... . . 90

Appendix D - Issue Category

Survey . . . . . . . .

Appendix E - Pilot Study Test.

Appendix F - Application for

Review of Research Project. 
Appendix G - Letter from

Human Research Review

Committee. . . . . . . .

Appendix H - Personal Data

Inventory . . . . . . . .

Appendix I - Pilot Study

Recruitment Letter . . . .

Appendix $J$ - Instruction Letter

to superiors . . . . . .

Appendix K - Instruction Letter

to Subordinates . . . . .

Appendix L - Informed Consent . .

Appendix M - Superior-Subordinate

Interpersonal Perception

Method . . ........

Appendix N - Performance

Appraisal. . . . . . . .

Appendix 0 - Recruitment Letter:

Final Study. . . . . . .

Appendix P - Instruction Letter to Subordinates: Final Study . .

Appendix Q - Instruction Letter to Superiors: Final Study . . .

Appendix R - Personal Data Inventory

Response Record: Public and

Private . . . . . . . .

Appendix S - Personal Data Inventory

Response Record: Superiors and

Subordinates . . . . . . . 


\section{LIST OF TABLES}

TABLE

PAGE

I Personnel Professional Survey Results . • . 30

I Issue Category Survey Results . . . . . . . . 34

II Pilot Study Data Analysis . . . . . . . . 47

IV Performance Appraisal Results: Whole Numbers . . . . . . . . . 50

V Performance Appraisal Results: Percentages . . . . . . . . . . 51

VI Private and Public Test Distribution and Return . . . . . . . . . 55

VII Corrected Item-Total Correlations . . . . . 57

VIII Performance Appraisal and Item Mean Scores . . . . . . . . . . . 58

IX Ten-Variable/Performance Appraisal

Pearson Correlation Coefficients . . . . 64

$\mathrm{X}$ SSIPM Issue Categories . . . . . . . . 65

$X I$ Individual Test Item and Performance

Appraisal Correlation Coefficients . . . 66 


\section{LIST OF FIGURES}

FIGURES

PAGE

I Levels of Perception . . . . . . . . 23

I Perceptual Comparisons . . . . . . . 25 
CHAPTER I

INTRODUCT ION

The world of work is filled with a broad expanse of occupations, trades and professions. The one common denominator across fields is people. Every form of work involves, at one point or another, communication with other human beings. Most often, work situations involve repeated faceto-face interaction with a few people. And, because organizations inevitably encompass hierarchies of responsibility and power, superior-subordinate relationships are involved. Breakdowns in communication are frequently cited as the cause of frustration and a lack of productivity at work. Communication failures are said to contribute to unrest and discontent within organizations. And, because organizations seek to attract and retain a qualified and effective work force, anything that blocks the effectiveness of employees is of great concern.

One of the key areas of research in communication is perception. A great deal of research has found vast perceptual differences between communicating pairs in organizations (Baird, 1977; Infante \& Gordon, 1979; Moore, 1974; Wexley, Alexander, Greenwalt \& Conch, 1980). The underlying assumption in much of the research is that perceptual differences create dissonant interpersonal relationships, 
which, in turn, reduce communication effectiveness (Foa \& Foa, 1976; Laing, Phillipson \& Lee, 1966; Likert, 1961; Korman, 1960; Maier, 1959; Triandis, 1959).

In an effort to understand the perceptual process and how it relates to interpersonal relationships, current research has focused on the relational or transactional, dynamic aspects of communication (Ber10, 1960; Goldhauber, 1974; Hastorf, Schneider \& Polefka, 1970; Laing, et al., 1966; Rogers \& Farace, 1975; Roloff, 1981; Smircich \& Chesser, 1981; Stewart, 1977; Wilmot, 1979). There has been recent identification of an emphasis on studying aspects of communication in context; $i . e .$, real rather than laboratory settings (Argyle, 1969; Goldhauber, 1974; Tucker, Weaver, BerrymanFink, 1981).

Based on the above and a vast area of related literature, it is clear that perception is a primary component of interpersonal communication (Hastorf, et al., 1970; Toch \& Smith, 1968; Verderber, 1980), and implicit is the assumption that close correspondence of perceptions is the basis for clear communication and good relationships. Between superiors and subordinates, an event around which perceptual differences become an issue is the performance appraisal of the subordinate by the superior at work (Baird, 1977; Heneman, 1974). Organizations use performance appraisals to motiviate employees toward improved performance, and as a basis for decisions regarding who to train, promote 
or replace. Both the importance of performance appraisal instruments and difficulties with the performance appraisal process have resulted in a plethora of research surrounding the subject. However, there is a dirth of instrumentation for determining more than mere perceptual agreement or disagreement between superior-subordinates. In addition, what relationships those perceptions have to the judgment by one of another seem to be an untapped area of study. While the rational manager's ideal would involve having performance appraisals based purely on direct and objective observation, and to see that workers are evaluated to the degree to which they fill the requirements of their job, several tendencies of rater bias are commonly known. Perceptions lie at the core of decisions that affect people at work, and . . "Human judgment enters into every criterion" (Latham \& Wexley, 1981, p.42).

What the relationship might be between the correspondence of perceptions and the judgments called for in the performance appraisal is the subject of this investigation. The intent is to use a method which taps the perceptions of superiors and subordinates regarding issues germane to their work relationship and to compare those perceptions to get an assessment of the superior's perceptions of the subordinate's performance at work in the form of a performance appraisal, and, subsequently to determine the strength and the direction of the relationships between 
these factors. Specifically, this research will involve:

(1) development of an instrument for reliably assessing the degree of correspondence of perceptions, consisting of issues of central concern to the superior-subordinate relationship; (2) administration of the developed instrument to superior-subordinate pairs, and the administration of the performance appraisal instrument to the superior member of those pairs; (3) analysis of data to determine the relationship between the correspondence of perceptions, and the outcome of the performance appraisals. The objectives will be achieved through item development and two cycles of data collection and data analysis.

It is anticipated that the result of this effort to identify issues germane to superiors and subordinates at work, the Superior-Subordinate Interpersonal Perception Method (SSIPM) may be a useful source of information for the assessment of the perceptual status between employees. Such an instrument could be used as a diagnostic tool in identifying areas of misperception and thereby create the opportunity for superior-subordinate dyads to achieve gains in communication effectiveness.

This study is, in part, response to the plea with which Hastorf, Schneider \& Polefka (1970) conclude their book, Person Perception:

We need to know more about how people get to know one another; such knowledge would entail the matching of one person's perceptions of another with the other's perception of himself... . We hope in- 
creased attention will be paid to the variables that influence the development of shared meaning, for it is the salient part of the fabric of all social life. (p. 103).

other current indications regarding the need for this kind of research are as follows: (1) wilmot (1979) suggested that joint perceptions be studied to strengthen our understanding of dyadic transactions; (2) Jabin (1979) comprehensively reviewed the empirical research in the area of superior-subordinate relationship communication and suggested that future research increasingly be developmental in nature and take into greater consideration the effects of situational variables; (3) Smircich \& Chesser (1981) researched two dimensions of interpersonal perceptions and concluded that :

- . [R] esearch must go beyond the level of agreement in order to explore fully the perceptions resulting from interaction between superiors and subordinates. Also, research must go beyond the level of understanding to include all four levels of the laing, et al., (1966) framework.

\section{Hypothesi.s}

The number of conjunctions (matching perceptions) in the superior-subordinate work dyad will covary with the superior's rating of the subordinate's overall performance. 
CHAPTER II

\section{THEORETICAL FRAMEWORK}

The ensuing theoretical review will be based on major developments within a systemic transactional approach to communication theory relevant to this investigation. Communication theory draws on several fields, as interests and areas of study are not mutually exclusive. Early communication theory consisted of linear, cause and effect models, and gradually evolved into the current view of communication as a dynamic, interactive process.

Early contributors to present models of transactional communication include social scientist George Mead (1934), who introduced the idea of the influence, through communication, that others have on the socialization process. Cottrell (1941) developed a role theory which suggested that, over time and through communication behavior, individuals become a stimulus for relatively invariant response patterns in one another. Dymond (1949) further contributed to the evolution of a systems approach in communication theory with her study of empathy. She found that the ability to put oneself in another's place, and to sense how he felt, was positively related to self understanding. The increased self awareness resulting from such an ability was said to 
assist one in understanding self-other patterns of interpersonal communication. This empathetic ability resulted in learning which was transferrable to new situations.

Thus, one's self image was part of interpersonal communication experiences (Dymond, 1949).

During the next decade many of the sciences and social sciences studied homeostatic systems involving feedback loops which allowed for self-correction (Swenson, 1973). This new process orientation also extended to communication, and the static sender-receiver approach received less attention. In its place, the focus shifted to interaction within a system. Bales (1951) theorized that present interactions were based on previous interactions from which communication developed expectations and behavioral dispositions. About the same time, psychologist B.F. Skinner (1953) developed his learning theory, which assumed that all human behavior was learned and is constantly modified by forces in the environment, including people. Skinner's work on operant conditioning served as a basis for later devlopment of the exchange theory by Thibaut and Kelley (1959) and Homans (1961), which involves trade-offs of closely allied resources. The exchange theory states that behavior which does not result in a valued reward will not continue, and behavior which results in punishment will also cease. The perception of these things is the individual's reality of how he views himself and his environment, and that is fundamental to this theory and others. 
A significant study of human interaction by Bateson et al., (1976) took place between 1952-1962. Although the subject of the study was schizophrenics and their families, the method of analysis focused on communication. The study found that the dysfunctional behavior of the schizophrenic patient was a result of paradoxical communication within the family. That finding was closely related to the work of R.D. Laing, (1972) who observed that in families, dysfunction of one reflects dysfunction of all. Thus, the study of reciprocal influence within a system of relationships has contributed to the development of theory.

The common approach to communication today reflects this progress. Communication is commonly viewed as a dynamic process. Brooks (1981) operationally defines the communication process as dynamic, systemic, adaptive, continuous and transactional. The systemic approach to study assumes that there are inputs, outputs, and feedback processes which tend to remain relatively stable over time (Argyris, 1962).

The previous overview of contributions to communication theory over time represents an effort to place the present research in context.

\section{Person Perception}

Person perception is a complex but fundamental phenonenonwhich provides a basis for human relationships. 
There is a mutually shared field; the person being perceived is also perceiving; (Taquirui \& Petrullo, 1958). Perception is a dynamic awareness that emerges as a result of a complicated weighing, ordering, and assigning of meaning to the selective process of observation and interaction. In the process, a whole host of factors and cues are involved, including past experiences, present context, present feelings and purposes, probable consequences, self concept and the impression of how others think and respond to us. We interpret what we see and hear, make inferences and assign meaning to people, information and events (Argyle, 1969; Hastorf, et al., 1970; Hinde, 1979; Toch, et al., 1968). To every situation we bring our demographic characteristics and our unique personality characteristics (Kolb, et al., 1971). Peception is selective; so that from the many things we see and hear, we remember only a few. Acts of great significance to one, may be trivial to another (Hastorf, et al., 1970; Laing, et al., 1966; Wilmont, 1979). In an effort to make sense of the world, we look for order and meaning, and what we do not find, we fill in; we impose structure upon situations and add information to what is incomplete.

There are many sources of error in the perception process so that people may not perceive things as they are (Argyris, 1966). Stereotyping is a generalization which limits the perceiver's view; further, it may have the force of a self-fulfilling prophesy (Snyder, et al., 1977; Wilmot, 
1975). Another psychological bias is the halo effect, which is lieniency through judgment, and was found to be statistically significant in two recent studies of work performance evaluations by Drory, et al., (1980) and Holzbach (1978). Perceptions are altered when one feels threatened, or feels a lack of trust, so that energy and attention are directed toward defending oneself rather than toward the message or the task at hand (Gibb, 1961). Another source of misunderstanding identified by laing, et al., (1966) is the use of projection by one or the other person, i.e., "one experiences the perceptual world in terms of one's phantasy (Laing, et al., 1966).

The very nature of perception accounts for vast differences between people. The implication is that the fewer the differences, the more helpful the perceptions. Accuracy refers here to the level of perceptual correspondence between communication partners. The importance lies in the extent to which perceptions correspond.

\section{Interpersonal Relationships}

Laing, Phillipson \& Lee (1966) theorized that ". • interpersonal systems can be seen as one of the determining influences upon perceptual process and structure . . and that human behavior is predominantly oriented toward making, maintaining and developing relations with others" (p.39). The dyadic relationship is viewed as a dynamic, ongoing 
process, which is continually mediated by the experience each person has of the other. Based on this theory, a person's experience is filled with his view of himself (direct perspective), and his view of the other (metaperspective), and his view of the other's view of himself (meta meta perspective). Further, "behavior even of itself does not directly lead to experience. It must be perceived and interpreted according to some set of criteria" (p. 10). Research by Dymond (1948) resulted in data generated by married individuals who completed a questionnaire from their own perspective and also predicted how his or her spouse would respond. The results indicated that happy couples had more understanding of each other and were more like each other in their self-descriptions than the unhappy couples.

Wilmot (1975) states;

The relational approach to studying dyadic pairs is so new that the effects of each relational configuration for a pair... is still unknown. In general, however, relational satisfaction appears to be enhanced by more agreement, understanding, realization, and feeling understood. Laing, Phillipson and Lee found, for example, that disturbed marriages, when compared to non-disturbed marriages, manifest more disagreement and more misunderstanding (p. 89).

In a dyad, differing interpretations disrupt communication. There are no isolated individuals in a dyad instead, the two are acting upon one another in what Laing, et al., (1966) refers to as: 
- . [T]he spiral of reciprocal perspective (p. 23) . . in a system constantly sustained by two agents and comprising of nothing other than their behavior and experience, action either 'internally' on self or outwardly through behavior on the other is the medium for effecting change or for negating change. (p. 26)

Misunderstandings are reported to have a dissonant effect on the people and the task at hand by Laing, et al., (1966). When misunderstandings take place, the dyad becomes inefficient; it, "is often due to negative selection, where there is avoidance of, or limited interaction between the members over an issue..." (Laing, et al., 1966, p. 43).

\section{Dyadic Relationships at Work}

There is significant work involved in forming relationships of some intimacy, intensity and duration (Levinson, 1978). Relationships are dynamic, diverse and complex. The word 'relationship' implies that interchanges take place over an extended period of time and with some degree of continuity, which well describes the regular interaction in a place of work. Each interaction is affected by interactions in the past, and may affect interactions in the future. Behaviors, perceptions and thoughts about the self and the other are confirmed or disconfirmed in the communication process (Hinde, 1979; Laing, et al., 1966; Wilmot, 1979). Relationships emerge and develop as accompaniments to ongoing activities which carry role expectations (Delia, 1980). Levinson (1970) states, "Every organization is a social 
system, a network of interpersonal relationships." Within that network, people are attracted to one another based on real or assumed similarities such as background, roles, values, situations, communication styles (Wilmot, 1975) and proximity (Waxer, 1978).

Work relationships are affected by the climate, which is a reflection of the prevailing assumption about human behavior of the organization (McCrosky, 1971). In a study of high authenticity relationships between superiors and subordinates, subordinates were found to have greater degrees of organizational commitment, job involvement, role clarity, and satisfaction (Smircich, 1978). Brown (1976) postulated that similarity of values is so important in superior-subordinate relationships, that if they are lacking, the relationship deteriorates. Argyris (1962) has studied the hierarchial interpersonal systems within organizations and found that the values of rationality and intellectual clarity are encouraged, while the expression of feelings is discouraged. This linitation in the kind of communication valued may act to suppress the development of work relationships which would allow a full understanding based on open and direct styles. In particular, a lack of trust was found to distort perception and inhibit cormunication behavior in a way that is damaging to organizations (Argyris, 1966; Mellinger, 1956).

Smircich and Chesser (1981) hypothesized that differ- 
ing superior-subordinate perceptions regarding work performance would be dysfunctional. Because prior research in this area had been limited to simple agreement or disagreement, they applied two levels of the Interpersonal Perception Method (IPM) (Laing, et al., 1966) to analyze perceptions on six dimensions: quality of work, quantity of work, dependability, ability to get along with others, initiative on the job, and overall performance. The superior-subordinate pair rated these items on the direct perspective (the way he perceived it) and on the metaperspective (the way he thought the other perceived it) and the two were compared for a measure of understanding or misunderstanding. The entire group of subordinates perceived that their supervisors wouldrate them higher than they actually did. The authors concluded that research must go beyond the level of agreement/disagreement and use all four possible comparisons on the instrument in order to fully explore perceptions within the superior-subordinate relationship.

Infante and Gordon (1979) identified interpersonal perception as the foundation of superior-subordinate relationships at work. Using secretaries and their superiors as subjects, and the IPM method of comparing peceptions, their investigation found that neither was able to accurately estimate how each was perceived by the other. The researchers speculated that perceptual inaccuracies should have negative effects on interpersonal communication because those with inaccurate beliefs would be more likely 
to make inappropriate assumptions about the expectations of the other. Although they foresaw that more accuracy could strengthen relationships, they suggested that it is also possible that a negative effect could result from believing that one has a negative perception of the other. They theorized that being perceived favorably by a superior would confirm the self-worth of the employee, and, therefore, should increase job satisfaction and performance. Superiors, as a group, underestimated how positively they were perceived by their subordinates. The superiors rated the subordinates more favorably on seven of eight items when the superior belieyed he or she was perceived fayorably by the subordinate, regardless of trait.

Perceptual accuracy as to what his superior expected of him, and the extent of compliance to those expectations, were found to be significantly related to job satisfaction of the subordinate and his work performance as rated by the superior (Green, 1972). Close correspondence of perceptions seems to facilitate communication.

\section{Performance Appraisal Theory}

Motivational theories are the underpinnings for performance appraisals. The current state of these theories was recently reviewed by Mitchell (1982). Most current papers are focused on information processing or social-environmental explanations of motivation, rather than need-based 
approaches, or approaches that are concerned with individual differences. Work on expectancy theory (desired and contingent rewards should be tied closely to behaviorl, goal setting (people work harder with goals than without them), and equity theory (people are motivated by a desire for fairness) are all considered information processing approaches. Theories contributing to social cue and social evaluation include focus on the job environment such as operant conditioning or job enrichment. Mitchell reported that social scientists define motiviation as "the psychological processes that cause the arousal, direction and persistence of behavior" (p. 81). His composite definition of motivation is that it

- . [B]ecause the degree to which an individual wants and chooses to engage in certain specified behaviors. Different theories proposed different reasons, but almost all of them emphasize an individual, intentional choice of behavior analysis (p. 80).

Another emphasis of arousal theories is that they are seen as current and highly related to task environment. Mitchell concluded that these theories do contribute to motivation. Latham \& Wexley (1981) and Latham \& Yukl (1975) state that goal setting theory is a concept indigenous to most, if not all motivational theory. Studies have repeatedly found that individuals with specific hard goals which have been set and/or accepted by the worker result in higher performances than people with easy goals or people who were simply trying to do their best. Added incentives improved performance 
only if the individual was committed to achieving specific, hard goals.

Reinforcement theory is identified by Latham \& Wexley (1981) as important because, "Beahvior is in part a function of its consequences" (p. 129). A reinforcer is any behavioral consequence that increases the frequency of a behavior. However, if the reinforcement is not contingent on behavior, then the behavior is not likely to increase.

Organizations base their use of the performance appraisal on the belief that well-developed performance appraisal systems increase the likelihood that they will retain, motivate and promote their productive employees. The heart of the performance appraisal is the definition of effective behavior through job analysis (a thorough review of abilities and skills essential to job performancel. It is the combination of performance feedback and the setting of specific goals based on this feedback, that enables the performance appraisal to fulfill its two most important functions of motivation and development. It is on the basis of an employee's motivation and training that decisions are made about that employee's retention, promotion, demotion, transfer, salary increases and termination (Latham \& Wexley, 1981).

Perception and judgment are exercised by managers, and "the instrument is only as good as the people who use it" (Latham \& Wexley, 1981, p. 71). It is a process of observing, 
recording and then communicating the results to the subordinate. Organizations try to reduce subjectivity through training of managers in the interest of equity for their employees (Latham \& Wexley, 1981). However, human perceptions are just that. "No instrument, no matter how carefully developed, can guarantee valid results" (Heneman \& Schwab, 1982L.

The purposes of performance appraisals are to motivate employees, and to use as a basis for decisions about where the person will go within the organization, or, indeed, if the person will stay. The two purposes are somewhat in conflict. "For example, the use of appraisals by superiors for judgment decisions almost certainly inhibits the subordinate's openness with, and trust in, the supervisor which is so necessary in using appraisals to aid development" (Heneman \& Schwab, 1981, p. 66).

The performance appraisal involves comparing actual achievement against established objectives. Although it seems reasonable to expect that subordinates would like to be measured on objective criteria, a study by Smith (1978) found that subjects favored some subjective criteria.

Vroom (1964), Atkinson (195]) and McGregor (1966) considered employee behavior to be a function of personal and environmental factors such as needs, incentives and expectations. No matter what the assumptions regarding the basis for behavior, fairness seemed to be an important issue to 
all. In a research project by Landy, et al., (1978):

Frequency of evaluation, identification of goals to eliminate weakness, and supervisor knowledge of a subordinate's level of performance and job duties were significantly related to perceptions of fairness and accuracy of performance evaluation (p. 75I).

\section{Smircich and Chesser (1981). state}

An awareness that has emerged from organizational behavior research is that superiors' and subordinates' perceptions can differ significantly. One issue on which these differences has been marked is the level of subordinate job performance. The implications of these differences can be viewed as dysfunction... (and) differences may signal ineffective or incomplete communications with subsequent dissatisfaction with the appraisal and reward process (p. 198).

Several studies indicate that subordinates who are more perceptually aware of their supervisor's work related attitudes receive higher performance appraisals (Green, 1972). A recent study by Wexley, Alexander, Greenwalt \& Conch (1980) examined the relationship of actual similarity and perceptual congruence with performance. Congruence between the manager's description of the subordinate and the subordinate's self description was significantly related to the manager's evaluation of the subordinate's performance appraisals.

In the interest of equity, and because current laws interpret the performance appraisal to be a test which must meet the requirements of the law, a great deal of interest has been centered on the development of behavioral scales (Heneman \& Schwab, 1982) which are based on observable behaviors. However, Levinson (1970) states that because 
the supervisor is involved in a relationship with the subordinate, subjectivity will inevitably be a part of his judgment.

\section{Summary}

The foregoing review of theory and research was designed to provide a framework for the field study to follow. It is evident that perception is the foundation for communication within relationships, and for judgment involved in the performance appraisal.

The previous review supports the idea that the more matching superior-subordinate perceptions, the greater the field of shared meaning within the dyad. Good communication, a good relationship and a good rating of employee overall work performance by the supervisor would seem to follow.

Conversely, by the very nature of the interdependencies of perception and the communication process within a dyadic relationship, it follows that the more mis-matching perceptions, the higher the likelihood of a reduced field of mutual experience. A poor relationship would involve poor communication and negative feelings, misunderstandings and disagreements and the judgment of the superior regarding the subordinate's overall work performance would be influenced by the lack of mutual perceptions.

In order to get a foothold into the highly complex and interrelated cycle of human perception, communication 
21

and relationships, it is necessary to break events down into components which can be talked about and analyzed. Therefore, the following chapter will describe an attempt to develop an instrument designed to allow such an analysis. 


\section{PERCEPTUAL MEASUREMENT}

\section{The Interpersonal Perception Method (IPM)}

The IPM is an instrument and a method developed by Laing, Phillipson \& Lee (1966) and can be used to examine the interperceptions of people within a relationship. The instrument developed in the present investigation, though different in item content, measurement focus, and empirical methodology, was built on the logic of interpersonal perceptual comparisons by Dymond (1949), and as refined in the IPM. Two individuals affirm or deny statements on three levels (direct, metaperspective and metametaperspective), and then the pairs of responses are compared, revealing conjunctions (matching perceptions) and disjunctions (mis-matching perceptions). For example, individuals respond to the following kinds of statements:

I feel that...

A. he respects me.

B. I respect him.

C. he respect himself.

D. I respect myself.

He feels that...

E. he respects me.

F. I respect him.

G. he respects himself.

H. I respect myself. 
He thinks that I feel that...
I. he respects me.
J. I respect him.
R. he respects himself.
L. I respect myself.

Individual responses to each test statement are compared. The arrows in Figure $I$, below (numbered $1-6$ ), represent comparisons of perceptions between levels (the direct perspective, the metaperspective and the meta-metaperspective) which results in measures of agreement or disagreeement, understanding or misunderstanding, realization or lack of realization of the perceptions of the other, and feelings of being understood or misunderstood.

\section{F IGURE I}

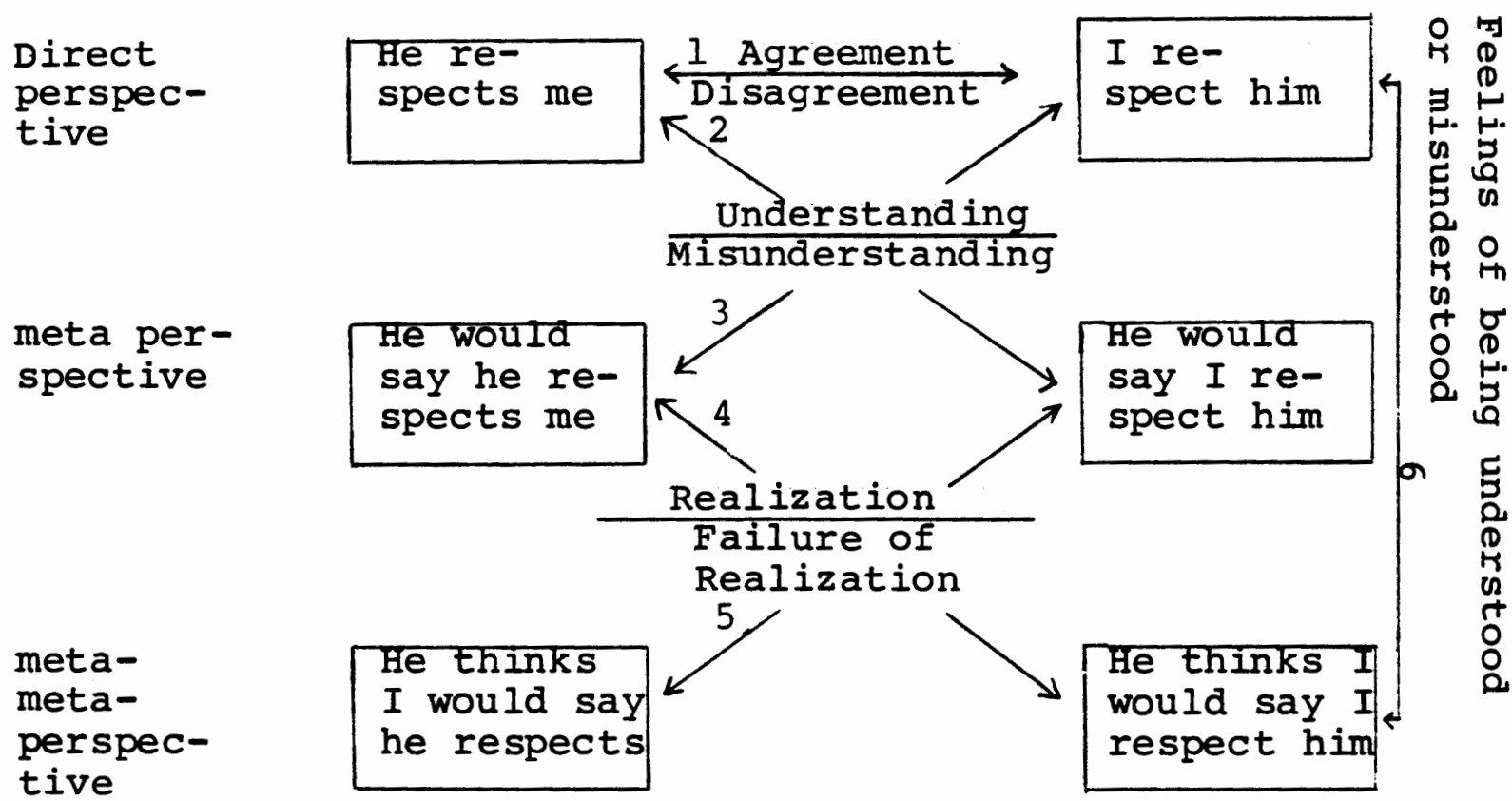

Adapted from Wilmot (1979); Grove \& Hays (1978)

At the direct level each member affirms or denies the aspects of an issue. At the realization level, each partner 
predicts how the other would respond to the same issue. At the realization level, each indicates the prediction he thinks the other would make of his own direct response.

Figure II depicts an example of perceptual comparisons between two people. Such comparisons at several perceptual levels provide a look at how accurately members of a pair can identify the other's perceptions. Alperson (1975) demonstrated the logical integrity of the IPM and the inferences drawn from it regarding "agreement", "understanding" and "realization". 


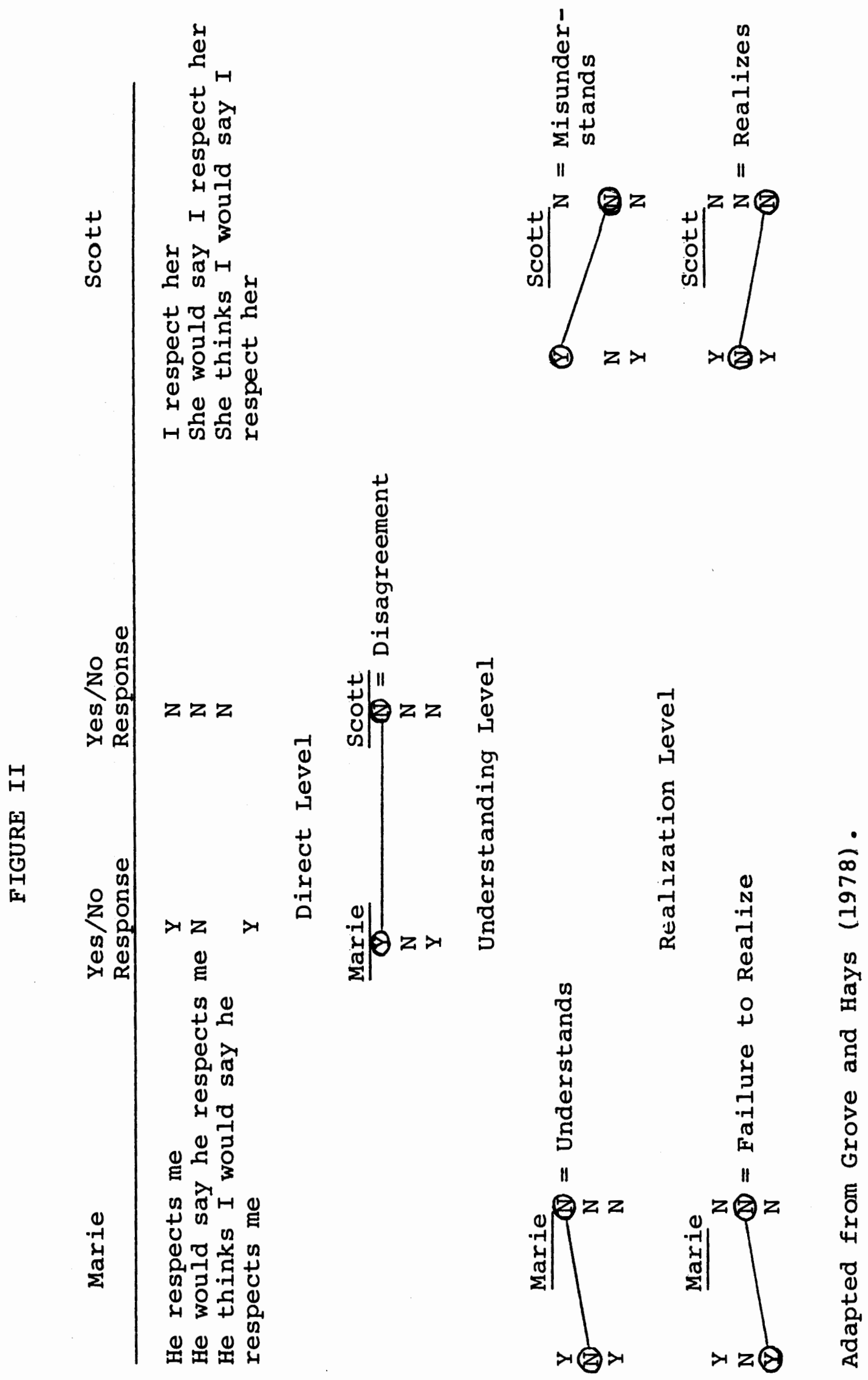


CHAPTER IV

INSTRUMENT DEVELOPMENT

Development of the Superior-Subordinate Interpersonal Perception Method (SSIPM) occurred in several stages: (Il six phases of issue reduction, including a survey of personnel professionals; (2) categorization of issues; (3) construction of issue format statements; construction of the pilot test; (5) assembly of the pilot test; and, (6) test response method and meaning. Each of the above phases of test development will be reviewed as they occurred over a time period of seven months.

\section{Phases of Item Reduction}

A compilation of potential issues resulted from the following resources: (1) 299 were compiled based on the researcher's review of the literature in the fields of communication, management and psychology, background reading in books used as references for this thesis, observations based on personal experiences, and a list of issues offered for consideration by Dr. Theodore Grove, Department of Speech Communication, Portland State University; and,(2) 60 from the origiral IPM. (See Appendix A for a complete listing of possible issues, and phases of their exclusion.) 
The first reduction phase involved elimination of duplicate issues, all negatively stated issues, and issues with negative connotatons, which accounted for 65 issues.

In the second phase, four issues judged as inappropriate to the work setting were discarded.

In phase number three, issues were deleted if they were judged by Dr. Alan Cabelly, Dr. Theodore Grove, and the researcher not to: (1) elicit a common interpretation; (2) elicit a minimal ambiguity; (3) refer to a relational issue; (4) be monotonic in item operating characteristic; or, (5) be of relative importance. Failure to meet any of the foregoing criteria resulted in the elimination of the item in question. This analysis reduced the list by 156 issues.

In phase four, five issues also appearing on a performance appraisal form being used in this study were eliminated.

Phase five consisted of eliminations based on a concensus between the researcher, Dr. Grove and Dr. Cabelly on the relative importance of all remaining issues. The meeting was called by the researcher because of concern regarding the length of the potential-issue-list. The next issue reduction phase involved asking personnel professionals to evaluate the issues. Because of the time which would be involved for each survey participant, a final effort was made to scrutinize the issues. This process 
narrowed the list by 15 .

Phase six involved a survey of personnel professionals which resulted in a reduction by 14 issues. The survey process will now be described.

\section{Survey of Personnel Professionals}

Twenty-five personnel professionals were identified by the president of The Portland Chapter of the Pacific Northwest Personnel Management Association as "experts" in that field. They were contacted by phone, the purpose of this study was explained, and their cooperation in rating possible test issues on relevance and understandability was requested. Eighteen personnel professionals agreed to participate in the survey; they were sent a letter and a survey. Participants were asked to rate each of 55 issues on a five point scale on the basis of their professional experience. Each issue was rated for relevance to the superior-subordinate work dyad and for understandability. Twelve completed surveys were returned, and 14 issues were removed from the master list on the basis of survey responses. Issues were deleted when rated as either : (1) poor by $70 \%$ of the respondents; or, (2l were not rated as excellent by $30 \%$ of the respondents; or, (3) did not receive a minimum mean score of 3 out of 5 possible points. (See Appendices B and $\mathrm{C}$ for the letter and survey. See Table I for survey results). 


\section{Issue Category Suryey of Academic Experts}

Under consideration at this time was the idea that issues could be divided into content categories of dyadic communication, attitudes or work behaviors. To determine category placement a survey was developed (Appendix D). The survey sought the expert opinions of nine Portland State University professors from the academic disciplines of communication, psychology, and business administration. A professor in each department secured the cooperation of three appropriate specialists within his department. Results are compiled in Table II. This content analysis of the issues resulted in a disparity of issue divisions, and it was subsequently decided not to divide the issues into categories on the test. The category divisions would, however, be used for final test data analysis. 

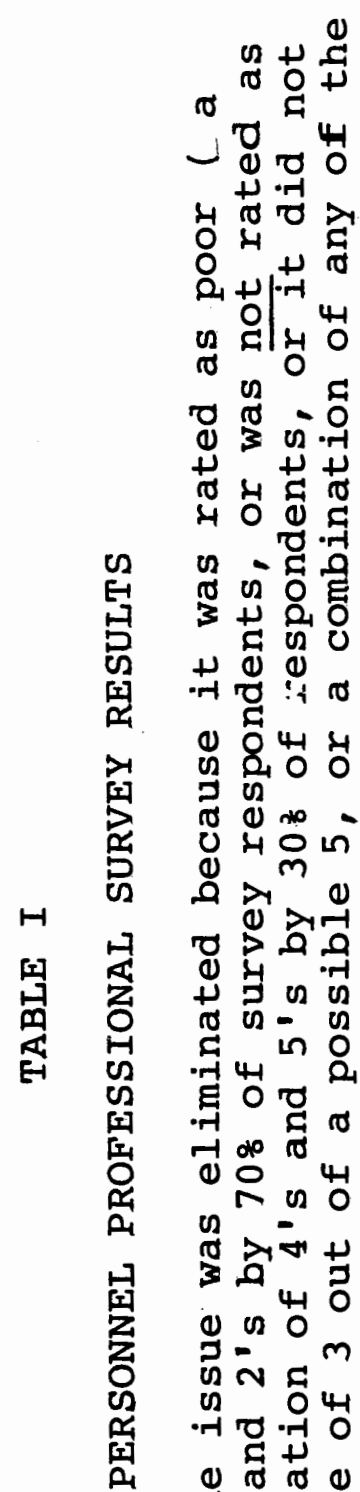

(1) क्ष 44

$\begin{array}{lll}0 & 0 \\ 0 & 0 & 0\end{array}$

\% 10 -

0 4 0 in

ด

गे 0

ช है

+4 ט

(0)

.

ह 0 ॠ

न1 do

$100^{\infty} 4-1$

on $=$

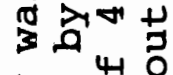

() $\boldsymbol{0} 0$

m

ט $N$ 息 4

-

E +

(1) त 10

U ज.

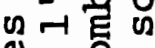

(1)

$+400$

엉

त

A

血

* प्ञ

- $\mathrm{A} \cdot \mathrm{H} 0$

잉

皃 00

언 4

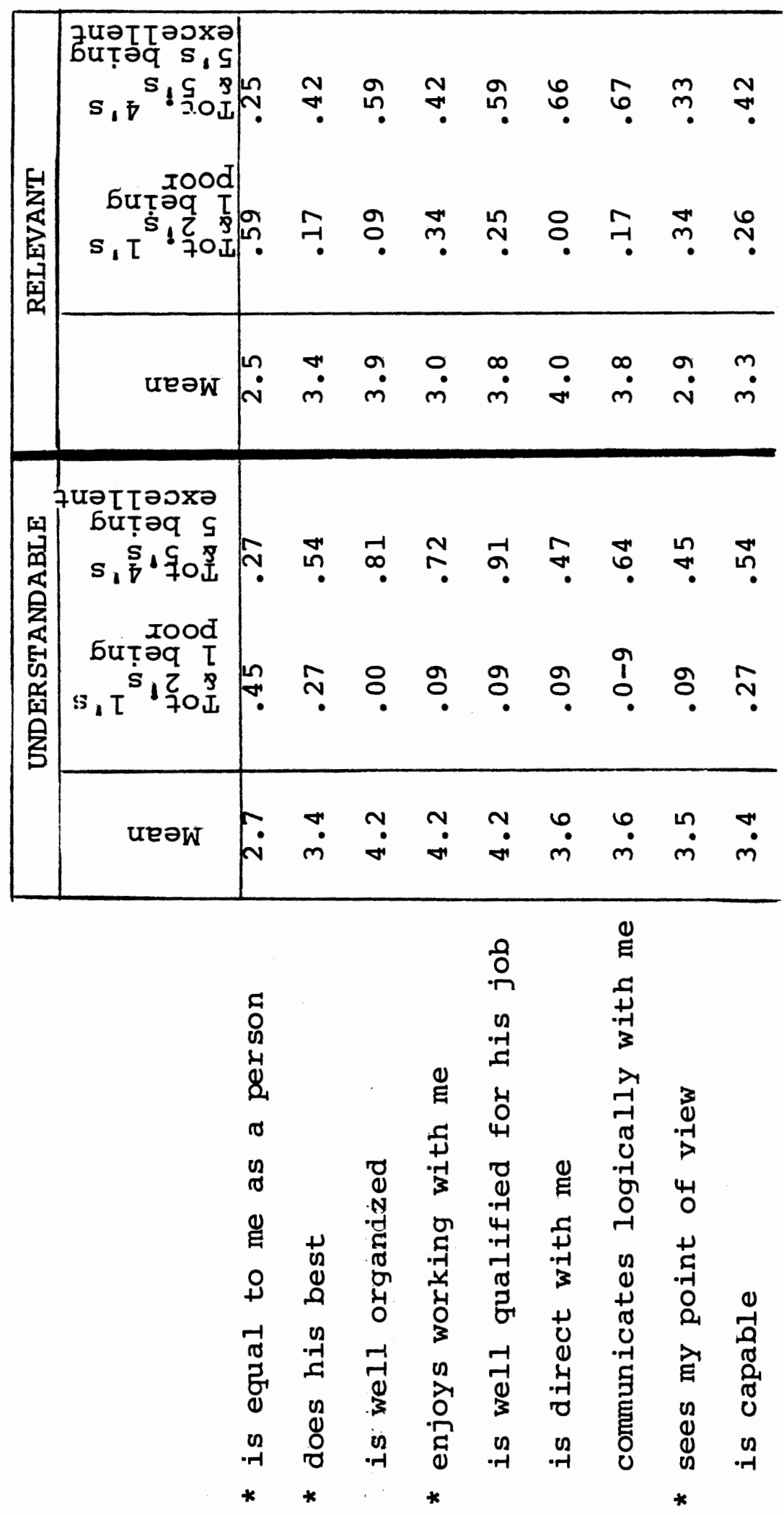




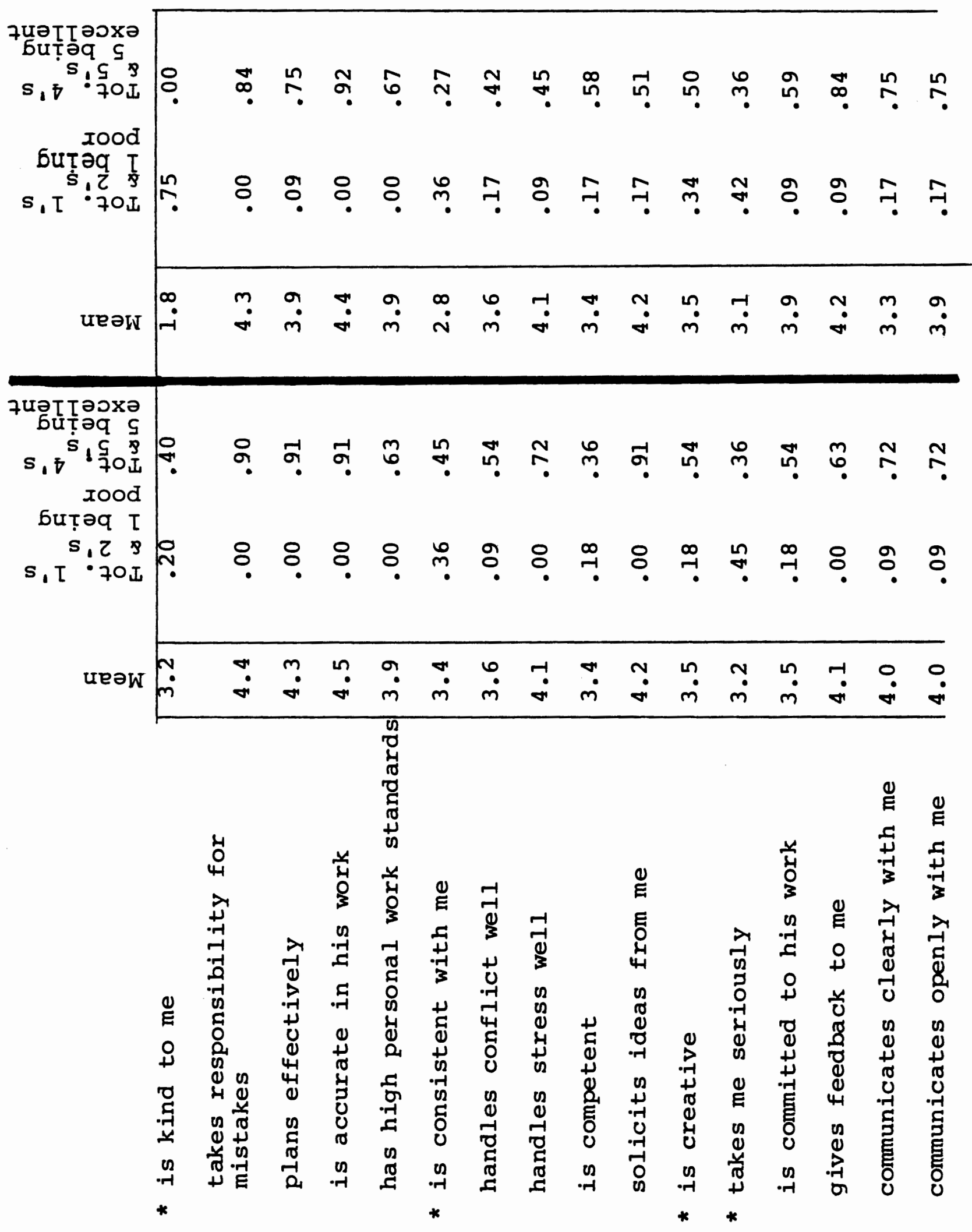









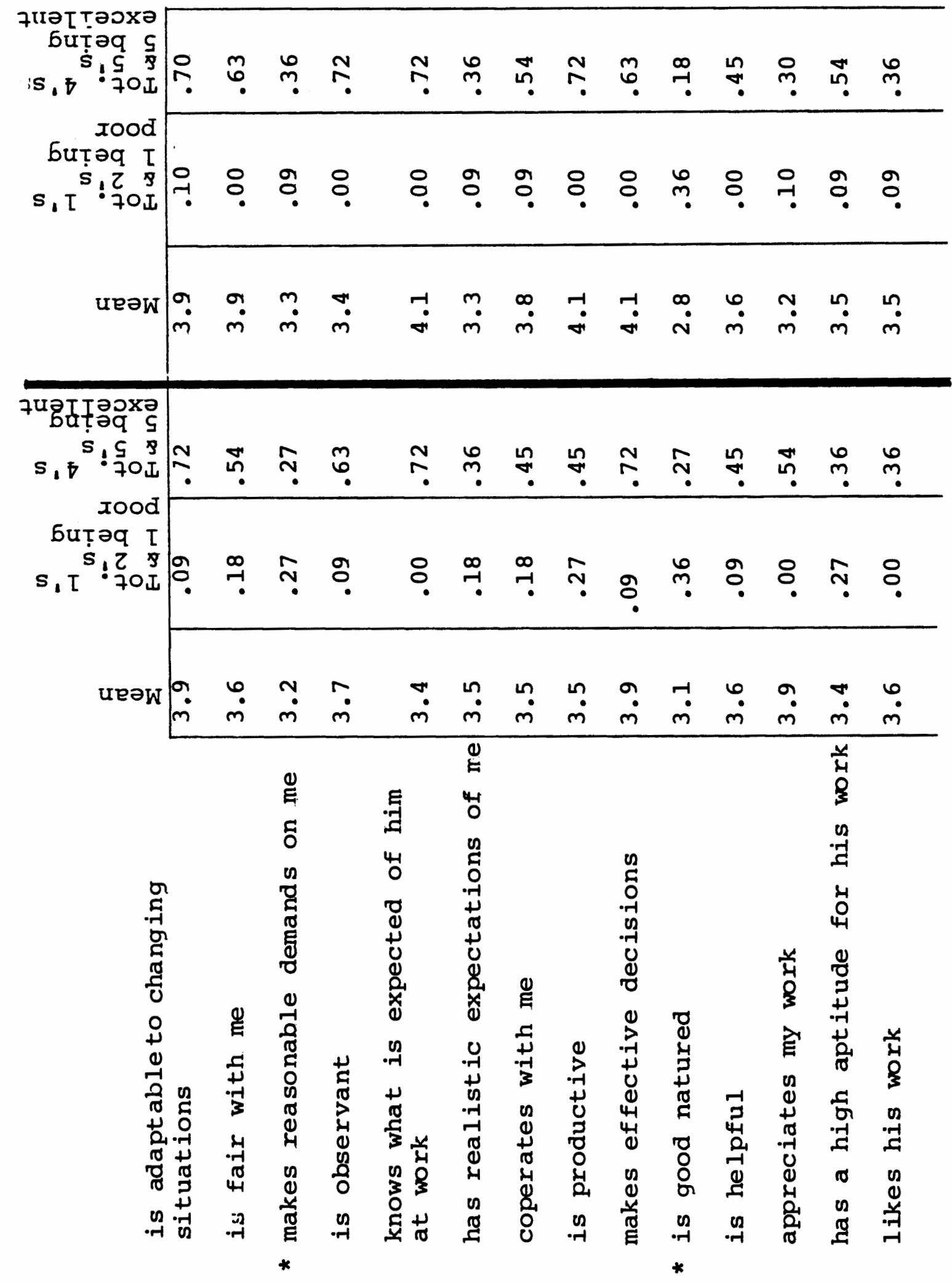


TABLE II

ISSUE CATEGORY SURVEY RESULTS

Category placement of 40 issues being considered for inclusion on the plot study test as determined by nine Portland State University professors from the academic disciplines of speech communication, business administration and psychology.

菌若

ATTITUDES (11 issues)

\begin{tabular}{|c|c|c|c|}
\hline $\begin{array}{l}89 \\
89\end{array}$ & $\begin{array}{l}1 \\
1\end{array}$ & $\begin{array}{l}18 \\
27\end{array}$ & $\begin{array}{l}\text { respects me } \\
\text { is self confident }\end{array}$ \\
\hline 87.5 & 2 & 40 & likes his work \\
\hline $\begin{array}{l}78 \\
75.5\end{array}$ & $\begin{array}{l}3 \\
4\end{array}$ & $\begin{array}{r}9 \\
14\end{array}$ & has high personal work standards \\
\hline & 5 & 11 & handles stress well \\
\hline 62.5 & 6 & 28 & is satisfied with my work \\
\hline 2 & 6 & 29 & $\begin{array}{l}\text { is adaptable to changing } \\
\text { situations }\end{array}$ \\
\hline 50 & 7 & 6 & takes responsibility for his \\
\hline & 8 & 23 & is honest with me \\
\hline & & 38 & appreciates my work \\
\hline
\end{tabular}

\section{DYADIC COMMUNICATION (16 issues)}

$\begin{array}{lllll}89 & 1 & 3 & \text { is direct with me } & \text { - } \\ 89 & 1 & 4 & \text { communicates logically with me } & - \\ 89 & 1 & 15 & \text { gives feedback to me } & \text { - } \\ 89 & 1 & 16 & \text { communicates clearly with me } & - \\ 89 & 1 & 17 & \text { communicates openly with me } & - \\ 89 & 1 & 25 & \text { really listens to me } & - \\ 87.5 & 2 & 13 & \text { solicits ideas from me }\end{array}$




$\begin{array}{ccclll} & & & \\ & & 0 & 0 \\ 0 & & & \end{array}$

\section{WORK BEHAVIOR (14 issues)}

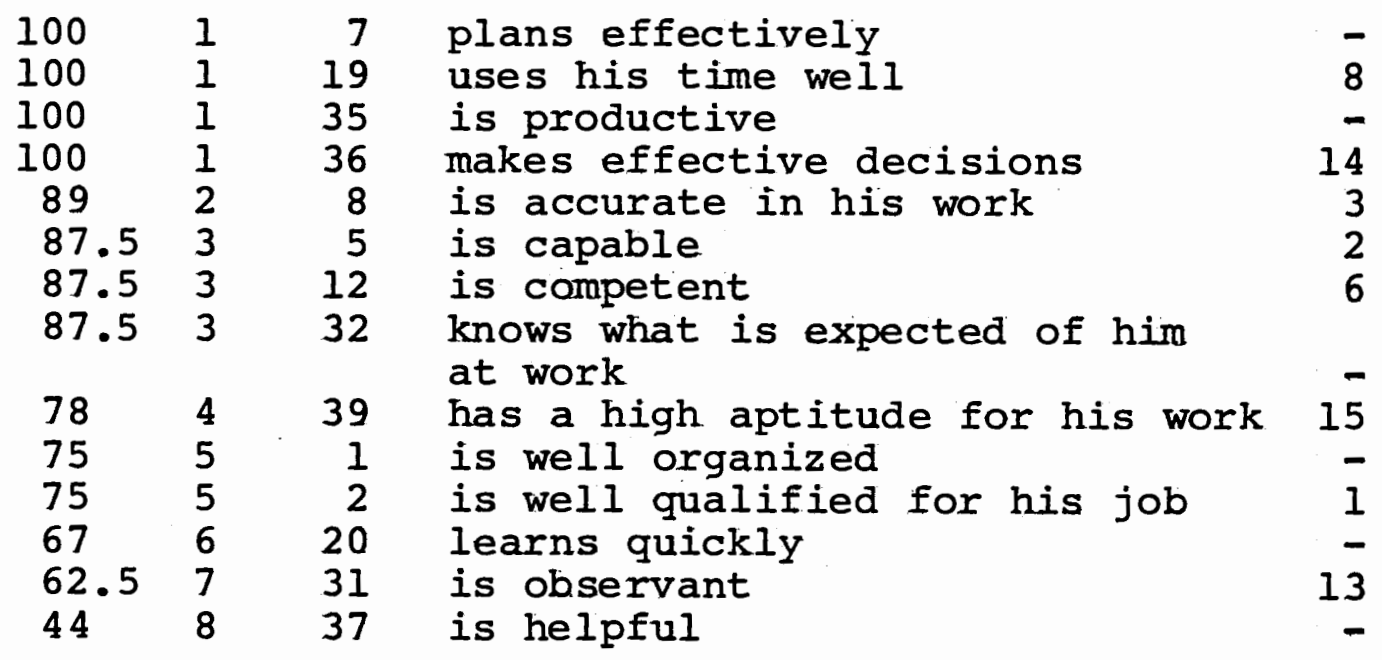




\section{Construction of Format Statements}

The original IPM (Laing, et al., 1966) utilized a statement format which was problematic. Issues which were relevant on an interpersonal level were often nonsensical on an intrapersonal level. Therefore, the intrapersonal aspect of the format, comprising $50 \%$ of the IPM was discarded for the SSIPM, so that all issues made sense interpersonally. A new structure was devised and the intrapersonal aspect was replaced by a salience (relevant and important) aspect for all test issues. For example, what would have been. . .

"I feel that...

A. he is honest with me

B. I am honest with him

C. he is honest with himself

D. I am honest with myself ",

became . .

"I feel that...

A. he is honest with

B. I am honest with him

C. he highly values honesty

D. I highly value honesty."

The new statements added a new dimension: the individual's value system. These statements would tap the respondent's views on the felt importance of an issue. The instrument would produce not only a measure of perceptual correspondence on issues, but on felt importance of each issue as we11. Pronoun gender was written into all statements to generate two forms of the test - one appropriate for respondents with female partners and one appropriate for respondents with male partners. 


\section{Assembly of the Pilot Test}

The pilot form of the SSIPM was comprised of 40 issues which were assigned test item numbers using a random number table (Rand Corporation, 1955). The pilot form of the SSIPM (Appendix E) was titled "Supervisor-Subordinate" rather than "Superior-Subordinate" in an effort to avoid offending anyone with the word "superior."

\section{Test Response Method and Meaning}

Perceptual responses to test items consisted of a forced choice method which required participants to accept or reject the issue statement by responding "yes" or "no". Responses were recorded by filling the appropriate space on a previously developed answer page for OPSCAN processing. Each of the 40 issues involved four statements which were repeated three times. For example...

I feel that...
A. he is competent
B. I am competent
C. he highly values competence
D. I highly value competence

He feels that...

E. he is competent

F. I am competent

G. he highly values competence

H. I highly value competence

He thinks that I feel that . .

I. he is competent

J. I am competent

K. he highly values competence

I. I highly value competence 
As shown above, test participants responded to the statements at three levels: the direct; the understanding; and the realization. At the direct level (I feel that....), each person affirms or denies the statements from his/her perspective. At the understanding level (he feels that.. .), each predicts how the other will respond to the same statements. At the realization level (he thinks that I feel that...), each predicts what his partner will respond regarding his feelings (he thinks that I think that he feels that...2. 


\section{CHAPTER V}

\section{METHODS}

The purpose of this research was to develop relevant understandable issues to be used in measuring perceptions of superior-subordinate pairs regarding those issues, and subsequently to determine if a statistical relationship existed between the correspondence of those perceptions and the superior's rating on the subordinate's performance appraisal. Perceptual responses to test items were obtained from superior-subordinate work dyads, and the correspondence of perceptions was calculated to determine the degree of perceptual matching.

\section{Overyiew}

The methods and procedures utilized in this study were as follows: (1) instrument development (Chapter IV); (2) a pilot study inyolving data analysis and issue selection (Chapter VI; (3) administration of the final test and the performance appraisal (Chapter VI); and, (4) analysis of results (Chapter VII).

The (SSIPM) test issue selection involved several stages. The initial form of the SSIPM consisted of 40 items and was implemented in a pilot study which included item 
analysis and reliability studies. Individual test items and total scores were analyzed. The final study provided data to assess the relationship of the dyadic perceptions with an external measure, the performance appraisal.

A total of 63 superior-subordinate pairs participated in this investigation in the pilot and final studies.

Their responses to a personal data inventory (Appendix H) allowed sample description by age, occupation, years in present position, years working together, their perception of how others would rate their relationship with their test partner, educational level and job satisfaction.

Test results were scored using the Fortran IV program IPALION (Grove \& Hays, 1978), and the subprograms "Reliability" and "Pearson Corr" from the Statistical Package for the Social Sciences (Nie, et al., 1981), commonly known as SPSS. A Honeywell 6640 computing system at Portland State University was used in processing all data.

\section{Pilot Study}

The purpose of the pilot study was to determine test item analysis. The pilot test, consisting of 40 test items, was administered to volunteer superior-subordinate co-workers in order to generate data for statistical analysis. 


\section{Human Subjects Research Review}

An application for a research review was made to the Portland State University Human Subjects Research Review Committee. The study purpose and procedures were set forth, and a copy of the proposed "Informed Consent" form for subjects was provided (Appendix F). The researcher was notified by letter that the cormittee was satisfied with provisions for protecting the rights and welfare of all subjects, and the project was approved (Appendix G).

\section{Subjects}

A total of 18 superior-subordinate pairs volunteered to take both the test and the retest two weeks apart. Fourteen dyads actually completed the first test; eleven dyads completed both tests. All participants met the criteria of having worked together for one year or more. Nine test pairs were employed at a Portland area hospital; two pairs were employed at a local law firm. Confidentiality was guaranteed and systematically maintained through coding of test, personal data forms and performance appraisal forms.

All subjects responded to the Personal Data Inventory (adapted from Roach \& Hays, 1977), which served to describe the responding population (Appendix H). Subordinates ranged in age from 20 to $60+$, with the largest group (368) 
reported as between 20-29 years of age. Eight out of eleven subjects reported their occupations as follows; legal secretary, R.N. (2), respiratory therapist, administrative assistant, housekeeping aide, radiology assistant, medical secretary, business office representative and shift manager. The mean number of years in the present position was 5.5 years (one subject reported working in the same position for 25 yearsl, while the average number of years working with the test partner was reported to be 2.9 years. Most subordinates (55\%) responded that others would rate their relationship with their superior as "good." More (45\%) had some college, and most (55\%) registered their job satisfaction level as "very satisfied".

The group of superiors ranged in age between 20 and 49, with the largest number $(64 \%)$ being between 30-39. Four. of 11 respondents listed their occupations as follows: R.N., business office manager, respiratory therapist and attorney. Superiors reported 3.8 years as the average number of years in their present position, and 3.2 as the number of years having worked with their test partner. Most superiors predicted that others would rate their relationship with their test partner as "excellent." Some college was reported as the average educational level (55\%). More superiors (45\%) marked their job satisfaction level as "very satisfied".

\section{Procedures}

The personnel manager at a local hospital was contact- 
ed, the research project was explained, and the request to seek volunteer subjects from within the ranks of the hospital staff was made. Copies of the "recruitment" letter, pilot SSIPM, test instructions, computer answer forms, and the informed consent form (Appendices $E, I, J, K, L$ ) were taken by the personnel manager to an administrative council meeting where it was decided that hospital employees could participate if they so desired. The hospital allowed employees to complete the test during work hours in return for an agreement to provide a report of general pilot study results.

The personnel manager circulated the "recruitment" letter and collected the first names of volunteer superiorsubordinate pairs. Test packets were prepared with the appropriate test form (male partner or female partner) and delivered to the hospital on the appointed day. Participants completed the forms, sealed them in the envelope provided, and delivered them to a hospital secretary. Three days later, the test packets were collected by the researcher. The process was repeated in two weeks for the retest. In the case of the participating law firm, test packets were delivered and collected from each individual by the researcher.

Participant test packets included a "Dear Participant" letter which contained instructions for taking the pilot form of the SSIPM, a consent form, a test, an answer page, and, 
for superiors, a performance appraisal form. The performance appraisal was superflous to the purpose of the pilot study, which was to determine the reliability of SSIPM test items by statistical analysis.

\section{Data Analysis and Test Item Selection}

All data analyses involved in this research were conducted with the assistance of various subprograms from Statistical Package for the Social Sciences (Nie, et al., 1981), and processed on the Honeywell 6640 computer. The data base consisted of responses which were processed by an optical scan program which converted data to punched cards for processing by IPALION. IPALION, a FORTRAN IV computer program, was developed by Grove \& Hays (1978) to score the original IPM and was used to score the pilot and final forms of the SSIPM. This was possible because the original response matching framework has remained the same. The scoring process compares and matches partner's perceptions reported for each item on the test, and computes summary scores and a record of the outcome for every set of compared perceptions. Through this process, IPALION adds to the information gleaned from the original IPM method of testing perceptions of an issue between people. The score for each test item ranges from 0-20; thus, a 40 item test score indicating perfectly matching perceptions on the SSIPM would be 800 . Test item matching scores and overall 
scale scores provided the data base for statistical analyses.

\section{Reliability Study}

IPALION output produced item, scale, and summary scores which were entered into data files for processing by the subprograms "Reliability" and "Pearson Corr" in the Statistical Package for the Social Sciences (SPSS). The first test resulted in a Cronbach's Alpha of +.91960 ; the retest produced a Cronbach's Alpha of +.68440 . The retest alpha was computed on the basis of 36 test items because four items (No's 13, 19, 29, and 39) lacked variability, and were excluded from the subprogram computation. Those four items had received perfect scores of 20 by the entire sample, an outcome which may not be altogether unlikely given the sample size of 11 dyads. The test-retest reliability analysis produced a Pearson product-moment correlation coefficient of +.8443 .

\section{Item Analysis}

Item analysis proceeded through inspection of each column in Table III, which displays the results of the subprograms "Reliability" and "Pearson Corr". Refer to Appendix E for the pilot study form of the SSIPM.

A review of Column No. 1, "Test, Retest Item Correlations", resulted in removal of the items which correlated negatively on the test-retest. These included items No. 1, 
$3,4,6,7,11,15,16,17,18,21,23,24,25,30,32,34$,

37 and 38. Inspection of Column No. 2, "Corrected Item/Total Correlations: Test," resulted in the elimination of item No. 13, which had a negative item/total correlation. A survey of Column No. 3, "Corrected Item Total Correlations: Retest", resulted in the elimination of items No. 20 and 22, which produced negative item/total correlations. Columns 4, 5, and 6, "Attitudes, Communication, and Work Behavior", present the results of a survey reported earlier in this study, where nine experts from the academic disciplines of psychology, business management, and communication analyzed all issues and placed them in one of the three categories. Of the survey issues only one did not result in at least more than $50 \%$ agreement from this content analysis. That issue, item No. 33, was eliminated. Column No. 7, "Inter-Item Correlation Matrix - Negative", served as a basis for computing the number of negative correlations removed through these item analysis procedures. The 24 items rejected in this process accounted for 195 (68\%) of the original 271 negative inter-item correlations in the 40 item correlation matrix (780 total correlations).

The surviving 16 items registered test-retest reliability coefficients ranging (Column 1) from +.6716 to +.0224 , with an average reliability coefficient of +.2056 . The SSIPM in the final form may be viewed in Appendix M. 
PILOT TEST DATA ANALYSIS

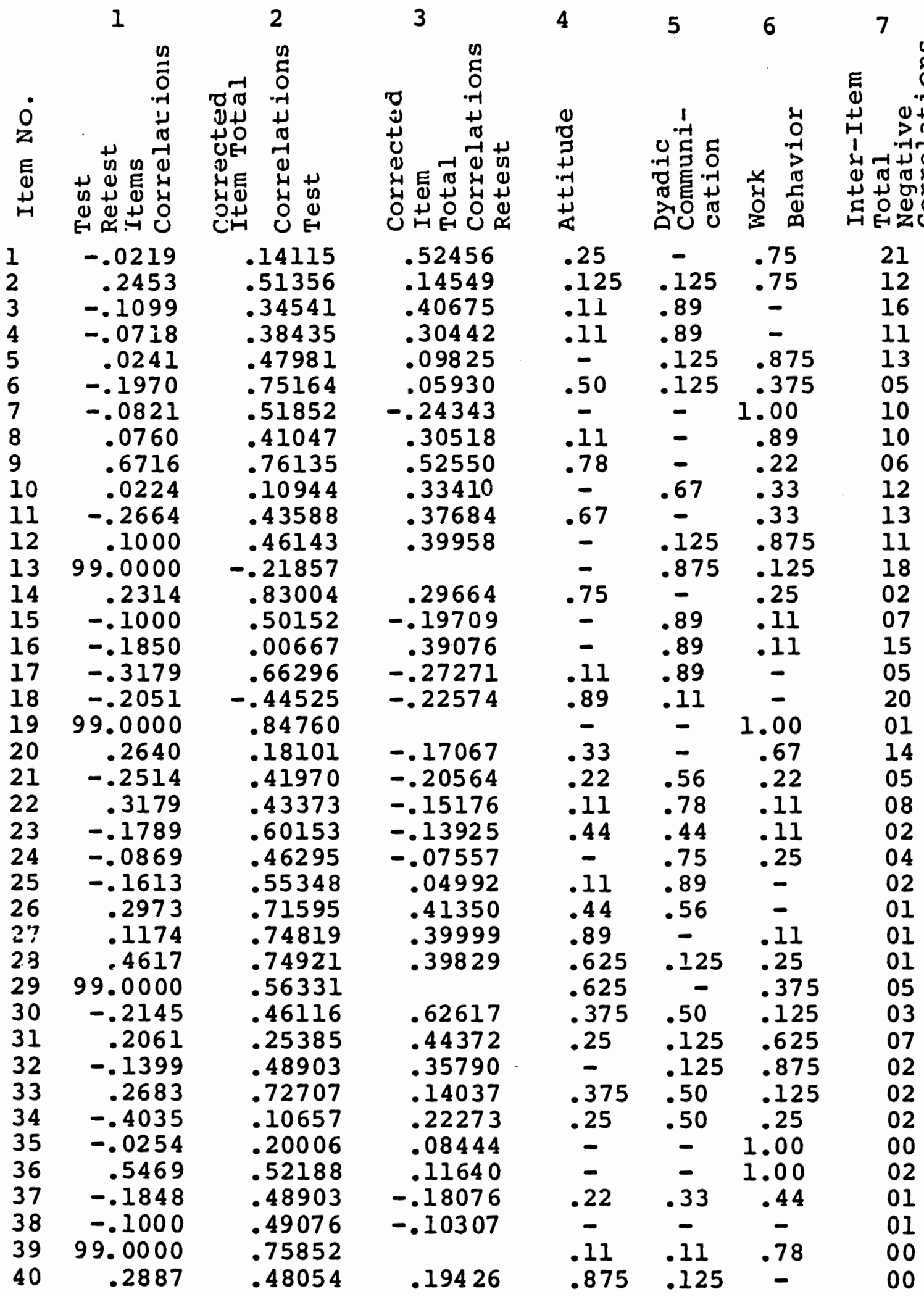


CHAPTER VI

FINAL STUDY

Hypothesis

This hypothesis will be tested in the final study:

The number of conjunctions (matching perceptions) in the superior-subordinate work dyad will covary with the superior's rating of the subordinate's overall performance.

\section{Description of the Performance Appraisal}

Several performance appraisal instruments used in various local organizations were reviewed by the researcher. This survey, and discussions with Dr. Alan Cabelly, Department of Business Management, Portland State University, led to the decision, with thesis committee approval, that using a variety of performance appraisal instruments would not be practical. Recent research by Smircich \& Chesser (1981) used six dimensions of performance to study perceptions between superiors and subordinates. Those six aspects of performance were adopted as the performance appraisal instrument for this study, and are as follows: quality of work; quantity of work, dependability; ability to get along with others; initiative on the job; and overall performance (Sims \& Szilagyi, 1975). Superiors rated their subordinate 
test partner on each aspect using a scale from $1-5$; 1 being poor, and 5 being excellent. The form may be viewed in Appendix N.

Scoring of the performance appraisal forms was accomplished by hand computation, and resulted in a percent score. On the five-point scale, zero was assigned for \#1 and 100 points were assigned for \#5. Therefore, \#1=0, \#2=25\%, $\# 3=50 \%, \# 4=75 \%, \# 5=100 \%$. The six responses were graded and then averaged for the performance appraisal score. See Table IV and V for performance appraisal results.

\section{Operational Definitions}

The performance appraisal is an instrument designed to measure and record the individual's work performance. Design of the performance appraisal begins with an analysis of job objectives and skills essential to the work. The design goals are for instrument validity, so that there is high correspondence between the workers! actual contributions and their measured contributions (Heneman \& Schwab, 1982).

The Superior-Subordinate Interpersonal Perception Method (SSIPM) is an instrument which results in measures of agreement/disagreement, understanding/misunderstanding, feelings of being understood/misunderstood, and realization or failure of realization within a dyadic relationship by comparing perceptions across levels (direct, metaperspective 


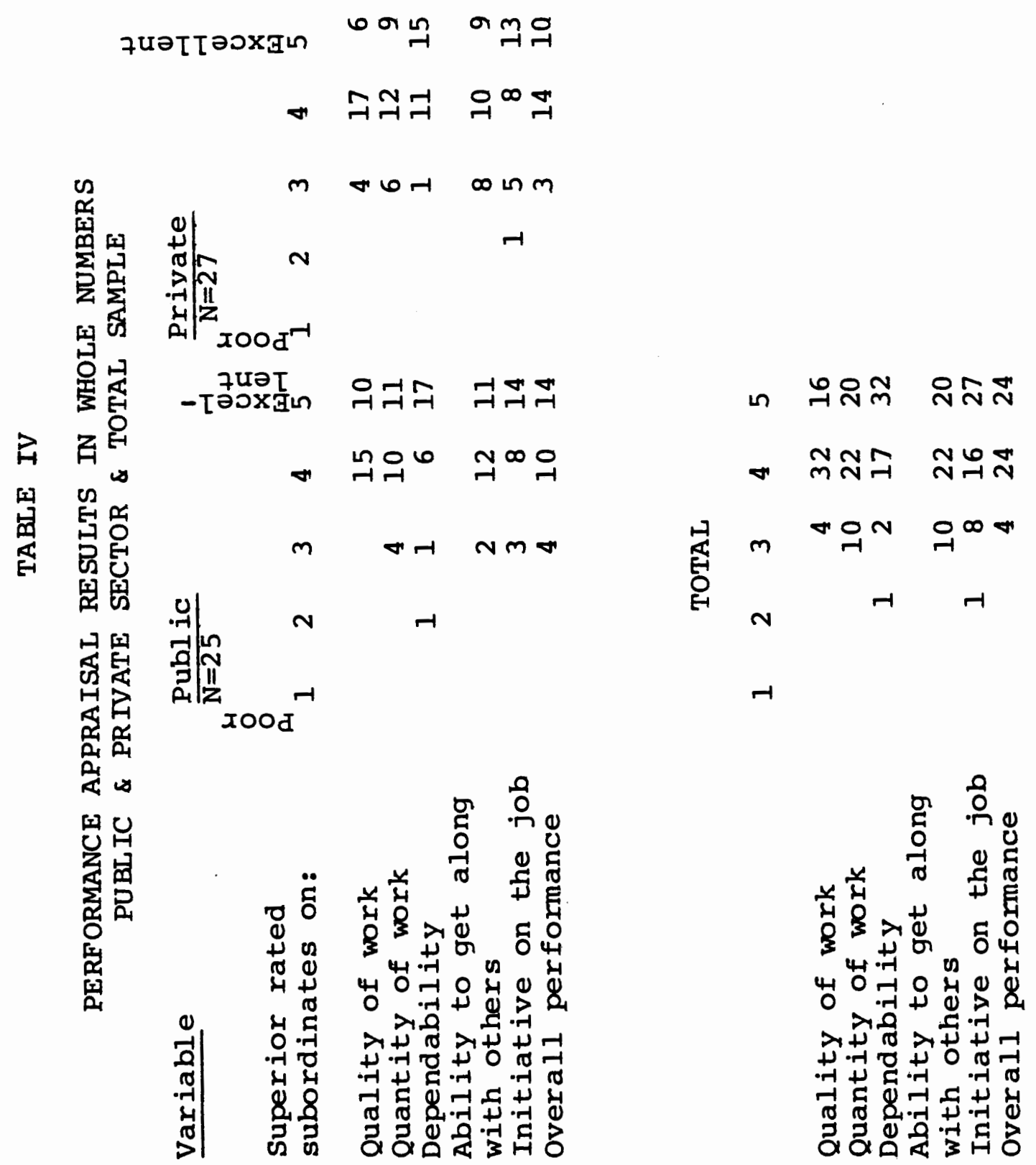




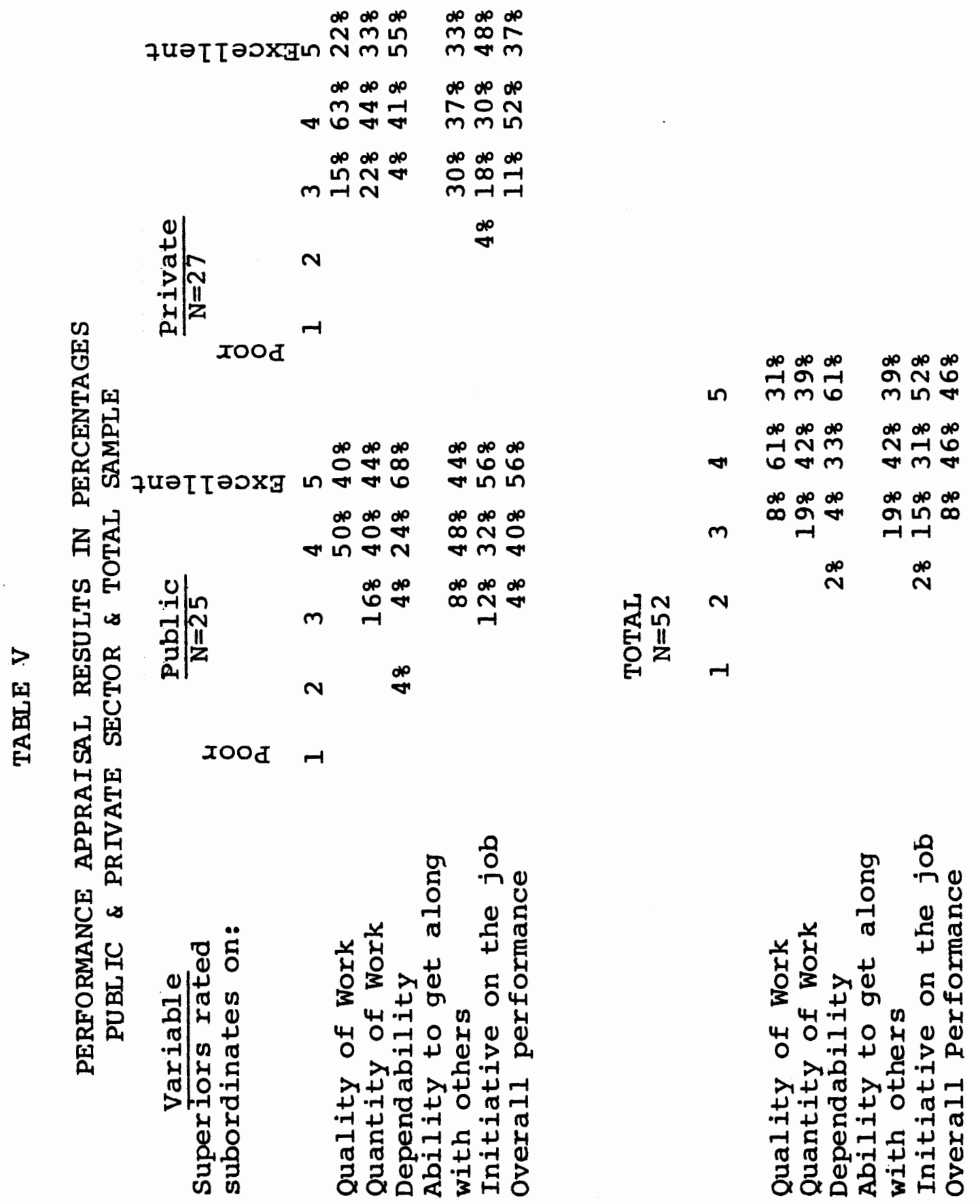


and meta-metaperspective). Conjunctions (matching perceptions) and disjunctions (mis-matching perceptions) result in scores which are analyzed to give measures of the above.

\section{Subjects}

A total of 52 superior-subordinate work dyads participated in the final study. All subjects were volunteers from either public or private places of employment.

Most superiors reported being between 30-49 years of age (738), but ranged in age from 20-60+. The average number of years that superiors reportedly served in their position was 5.7 years, and the mean number of years reported for working with their test partner was 3.9. As a group. more superiors judged that friends who know would rate their relationship with their subordinate as excellent (50\%) or good (408). All superiors finished high school, a few held a doctorate or other professional degree (48), and more (318) reported having a master's degree. More superiors marked their job satisfaction level as "very satisfied" $(458)$.

Subordinates in this study were mostly between 20-39 years of age (75\%). The mean number of years reported for having worked in that position was 3.6 , and the average number of years having worked with the superior test-partner was 3.7. Subordinates ranged in educational level from "did not finish high school", (4\%), to holding a master's degree 
(28), with the largest portion of the group reporting "some college" (448). Most subordinates predicted that friends would judge their relationship with their superyisor as "excellent" (56\%). The largest number of subordinates reported that they were "satisfied" (37\%) with their job. For a complete breakdown of personal data from public and private sector superior-subordinate subjects, including occupations, see Appendix $R$ and $S$.

\section{Procedures}

Several contact persons within local organizations were identified through the suryey of personnel professionals described previously. Other personnel managers were suggested by Dr. Alan Cabelly, or were persons known by the researcher. Generally, phone contact was made, the research was briefly described, the need for subjects was made known, and an appointment was requested. Personal appointments concluded with a decision regarding participation, or an explanation of the decision-making process within the organization. Follow-up appointments were arranged with two managers; others dealt with the request within the organization, and notified the researcher by phone regarding the decision. Fourteen organizations were approached, and eleven (798) agreed to cooperate to some degree. Three publicly funded organizations participated, 
supplying 50 superior-subordinate pairs as volunteer subjects. Eight private organizations participated, providing 52 superior-subordinate pairs who were willing to participate as subjects. Generally, there was reluctance to participate on the part of private organizations for the stated reason of economic hardship. Therefore, many private organizations were involved minimally. All participating organizations were promised a written summary of study results.

With organizational approval, "recruitment" letters (Appendix Ol were sent to possible superior-subordinate pairs identified by the personnel manager or an appointed assistant. Two organizations preferred to bypass the "recruitment" letter phase, and simply requested that the researcher deliver a specified number of test packets on the appointed day; the agreement being that they would try to give them out to willing participants. The recruitment letter requested that volunteer participants submit their names as pairs to a person in the organization, and it also specified the dates for the test period. There was a one week time period allowed for subjects to receive, respond to and return their test packets. Other procedures were identical to those used in the pilot study, and included test-taking directions in the form of a "Dear Participant" letter (Appendix P and Q). See Table VI for a breakdown of the distribution and return of test packets within organizations. 
TABIE VI

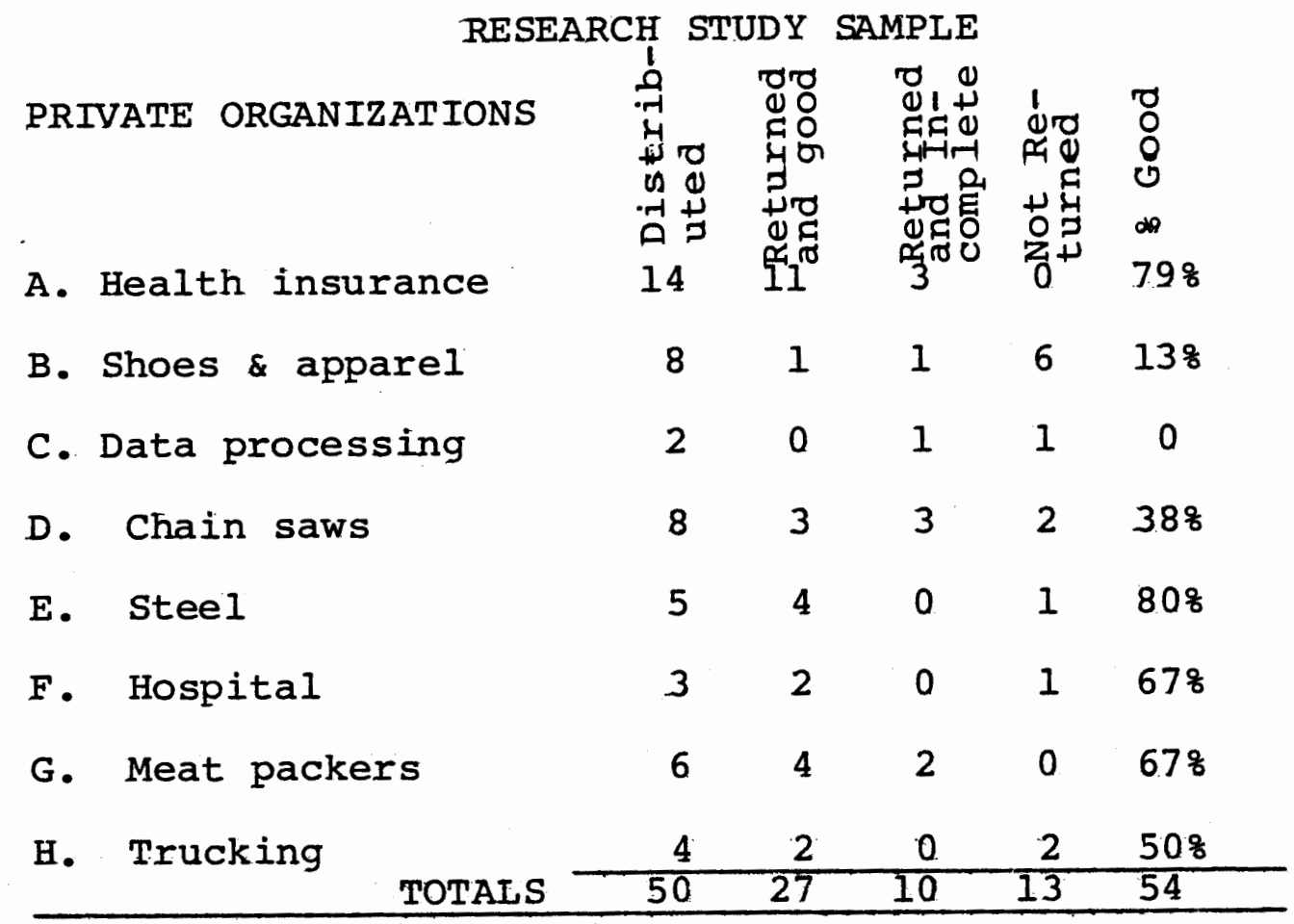

PUBL IC ORGANIZATIONS

\begin{tabular}{|c|c|c|c|c|c|c|}
\hline I. & County agency & 14 & 8 & 0 & 6 & $57 \%$ \\
\hline J. & State agency & 18 & 10 & 4 & 4 & $56 \%$ \\
\hline - & $\begin{array}{l}\text { Educational } \\
\text { institution }\end{array}$ & 18 & 7 & 3 & 8 & $39 \%$ \\
\hline & TOTALS & 50 & 25 & 7 & 18 & 508 \\
\hline
\end{tabular}


CHAPTER VII

RESULTS

The following presentation of results of the final study involve reports of : (1) reliability of the SSIPM; (2) mean scores on the SSIPM items; (3) test of hypothesis; (4) the global interpretation; (5) the role interpretation; and, (6) the issue interpretation.

\section{Reliability of the SSIPM}

The SSIPM produced a Cronbach's Alpha of +.76189 as a measure of internal consistency. Analysis of the corrected item/total correlation coefficients showed that four of the test items registered negative correlations. Only two of the positive 12 items exhibited correlations of less than +.40 . Coefficients ranged from +.25466 to +.79002 , with an average positive reliability coefficient of +.53975 . The corrected item/total correlations produced by the SSIPM in the final study are listed in Table VII.

Inspection of the inter-item correlation matrix showed that a total of 27 negative correlations (23\%) were computed out of a possible total of 136 .

\section{Test of Hypothesis}

The hypothesis was corroborated by this investigation. 
TABLE VII

CORRECTED ITEM-TOTAL CORRELATIONS

SSIPM RELIABILITY

Variable

Corrected Item-Total

Correlations

Item No. 1

.45096

3

.58453

.34175

4

.57962

.40725

6

.25466

7

8

.51909

9

10

11

12

13

14

15

16

$-.10418$

.65148

$-.17814$

.69614

.49711

.79002

.70466

$-.35380$

$-.32820$

Reliability Coefficients

Alpha $=+.74187$

Standardized Item alpha $=+.76189$ 
TABLE VIII
PERFORMANCE APPRAISAL AND ITEM MEAN SCORES
$\mathrm{N}=52$

Variable

Performance Appraisal
Item No. 1
2
3
4
5
6
7
8
9
10
11
12
13
14
15
16

Mean

Scores

82.8077

18.1923

18.9231

18.5385

18.5577

15.2885

19.1923

17.6923

16.0192

18.5000

16.2500

17.8462

17.7500

17.9231

19.7692

18.1346

17.6538
Standard

Deviation

3.3139

2.5193

2.3884

2.9400

3.9325

2.2927

3.6758

4.3227

11.0764

4.7522

7.2094

7.1425

6.0968

7.5812

3.9009

4.1106 
Statistical analysis did not indicate a strong relationship, but did confirm a direct and significant positiye relationship between the performance appraisal scores and the SSIPM scores, The SSIPM performance appraisal correlation coefficient was +.2779 with a significance of .046 . The SSIPM scores and the performance appraisal scores covary as hypothesized.

\section{The Global Interpretation}

There was an oyerall pattern of a positive relationship between the performance appraisals and several variables. There were no negative correlations across a broad range of indicators, including: communication issues; attitude issues; work behavior issues; levels of understanding and realization between partners; the total number of matching perceptions; perceptions of the issue content and issue salience; and, the number of individual accurate perceptions of one's co-worker made by superiors and subordinates. Coefficients resulting from the correlation of performance appraisal scores and 10 other variables are reported in Table $\mathrm{x}$.

\section{The Role Interpretation}

The total subordinate perceptual correspondence (SSIPM test scores) and the performance appraisal scores produced a positive correlation of +.3068, achieving significance at the .013 level. The total superior per- 
ceptual correspondence (SSIPM test scoresl and performance appraisal scores produced a slightly lower positive correlation of +.2737 , achieving significance at the .025 level.

\section{Response Level Interpretation}

Three perceptual levels of conjunctions were analyzed for relational correspondence. A positive significant correlation of +.3014 was found between the understanding level of superiors and subordinates and the performance appraisal scores. The understanding level results from comparing the direct perspective and the metaperspective (see page 23) and involved each test partner predicting how the other would respond to the same statement.

The correspondence of perceptions at the realization level apparently had a weaker relationship to the performance appraisal process, as it registered a low correlation of +.1814 , which did not achieve statistical significance. Scores for the realization level result from comparing the metaperspective and the meta-metaperspective (see page 231. The outcome was determined by comparing each party's realization response with the other's understanding response.

Each person's realization responses were compared with his own direct responses, giving a measure of the extent to 
which that person feels understood. Feelings of being understood, when correlated with the performance appraisal, produced a positive correlation of +.22 .

\section{Issue Category Interpretation}

As previously described, test issues were divided into the categories of communication, attitude, or work behavior through a content analysis by experts. Table XII indicates the categorization of issues on the SSIPM. In an effort to determine which category of issues might have the strongest relationship with the performance appraisal, the disparate numbers of issues in each category were divided by the total number of items to achieve an equal weighting of each category. Two categories resulted in a significant, positive correlation with the performance appraisal scores. The correlations produced were strongest with the work issues at $+.3008, P=.015$, followed by the communication issues at $+.2314, P=.049$. The attitude category also produced a low, positive correlation of +.2217 narrowly missing the significant leyel at $P=.057$.

\section{Issue Interpretation}

Each individual test item was associated with the performance appraisal for eyery dyad as reported in Table XI. Test item No. 1 (is qualified for his job) and No. 13 (is observant) correlations reached significance at the .040 
leyel, registering coefficients of +.2860 and +.2864 , respectively. No other individual item correlated with the performance appraisal significantly; positive correlation coefficients ranged from +.0382 to +.2502 . Items No. 6 and 16 produced low, negative correlations. Except for two, the test items as a whole were weakly but positively related to the performance appraisals.

The two-part nature of the SSIPM statement format has to do with the content of the issue in the first two statements, and the importance of the issue in the last two statements. An example is:

". . he hanales conflict well

- - I handle conflict well

- . he highly values handling conflict well

- . I highly value handling conflict well."

A correlation coefficient for issue content with the performance appraisal of +.1829 was obtained, which lacked significance at the .05 level. The correlation between correspondence of issue salience and the performance appraisal was +.2991 , significant at the .016 leyel. 
TABLE IX

SSIPM ISSUE CATEGORIES

COMMUNICATION ISSUES

Test Item No. 5 handles conflict well

9 is candid with me

ATTITUDE ISSUES

4 has high personal work standards

7 is committed to his work

10 is self confident

11 is satisfied with my work

12 is adaptble to changing situations

16 likes his work

WORK BEHAVIOR ISSUES

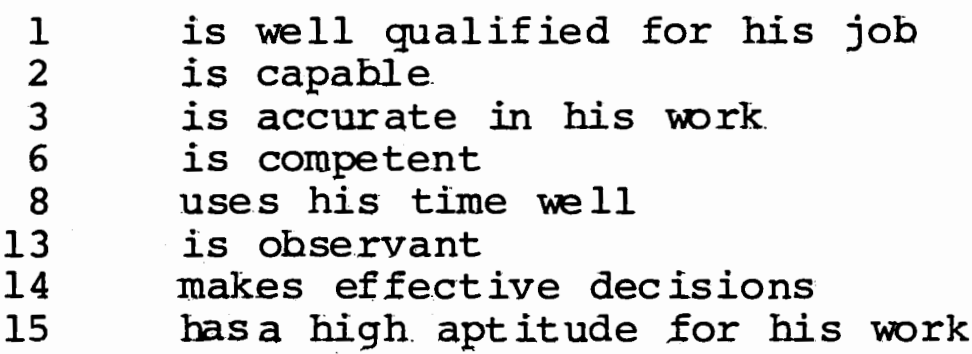


TABLE X

TEN VARIABLE/PERFORMANCE APPRAISAL PEARSON

CORRELATION COEFFIC IENTS

VARIABL ES

CORRELATION

CORRELATED

COEFF IC IENT

PROBABIL ITY

Issue Category

Interpretation

Test of Hypothesis:

Total conjunctions on all issues with *PA

Issue Category Interpretation:

Total conjunctions from all levels

of response for all communication

items (item \#5 and \#9) with PA .2314

Total conjunctions from all levels of response for all attitude items (items \#4, 7, 10, 11, 12 \& 16) with

$\mathrm{PA}$

Total conjunctions from all

levels of response for all work

behavior items (items \#1, 2, 3,

$6,8,13,14 \& 15$ l with $\mathrm{PA}$

.3008

Response Level Interpretation:

Understanding level responses

across all issues with $\mathrm{PA}$

.3014

Realization level responses

across all issues with $\mathrm{PA}$

Feelings of understanding responses across all issues with PA

Issue Interpretation:

Issue content of all issues with PA 
VARIABLES

CORRELATED
CORRELATION

COEFFIC IENT

Issue salience of all issues with PA

.2991

.016

Role Interpretation:

Total supervisors' conjunctions on all levels with PA

Subordinates' conjunctions on all levels with $P A$

.3068 .013

* PA = Performance Appraisal Score

Note: The "Global Interpretation" on page includes all of the above correlation coefficients. 
TABLE XI

INDIVIDUAL 'PEST ITEMS \& PERFOPMANCE

APPRAISAL COEFFICIENTS

\section{Variable}

PA

1

2

3

4

5

6

7

8

9

10

11

12

13

14

15

16
PA/Item Corr.

.2860

.2437

.0382

.1241

.1234

$-.0988$

.0046

.9987

.2502

.0458

.2370

.1610

.2864

.2473

.0950

$-.0777$

\section{Probability}

.040

.082

.788

.381

.383

.486

.974

.951

.074

.747

.091

.254

.040

.077

.053

.584 
CHAPTER VIII

\section{DISCUSSION}

The results of this study support the hypothesis that the performance appraisal process is positively related to the number of matching perceptions between supervisorsubordinate work dyads. The present study finds that there is a direct and significant relationship between the performance appraisal and the degree of accuracy in interpersonal perceptions. Findings suggest that when the superior and subordinate achieve a more closely shared field of meaning, the performance appraisal of the subordinate is higher. Conversely, when perceptions do not closely correspond, superiors rate their subordinate's performance less favorably indicating that a lack of closely corresponding perceptions is dysfunctional.

The SSIPM total score is based on the number of matching perceptions across all issues and levels. The hypothesis confirmed in the present investigation did not deal with the relative importance of the four levels (agreement/disagreement, understanding/misunderstanding, realization/lack of realization, feelings of understanding/lack of understandingl; rather, it predicted that the sum total of matching perceptions would covary with the performance appraisal. The 
results suggest that subordinates may benefit from working at communication which increases the field of perceptual correspondence with their superior. Superiors should be aware that a field of closely corresponding perceptions is related to their judgment of the subordinate's performance. These findings account for only about $9 \%$ of the relationships involved with the performance appraisal. Findings do not rule out the possibility that performance is rated more highly because it is actually better when perceptions between superiors and subordinates correlate more closely. However, cause and effect are not investigated here.

Item analysis suggests several important features of the SSIPM. Reliability as indicated by Cronbach's Alpha was moderately high at +.7619 , lending credibility to the internal consistency of the measure, but leaving room for improvement. Item discrimination based on corrected item total correlations shows four negative correlations which constitute extraneous "noise" within the instrument.

The categories of communication and work behavior were positively and significantly related to the performance appraisal. The strongest relationship was with work behaviors, suggesting that when superiors are judging a subordinate's work performance, those issues are more highly related than other issues considered here. Study results indicate that it is most important to attain perceptual 
accuracy on work issues. In particular, perceptions about being qualified for one's job and on being observant are important. Those two test items, when correlated independently, were found to be significantly and positively related to the performance appraisal. In view of these results, subordinates might benefit from clearly commuicating about the work issues on this test, and, specifically, about their observational abililities and their qualifications for their job.

The two items categorized as communication issues on the SSIPM were "is candid" and "handles conflict well", so it would behoove subordinates to practice those. However, subordinates would first need to ascertain what their superior perceives as desirable about those issues. Superiors should be aware that a relationship exists between those issues and their judgment of the subordinate's performance. According to other findings, the perceptual level of understanding between superiors and subordinates is significantly and positively related to the performance appraisal process. Open and clear communication would facilitate closely corresponding perceptions, while poor and/or defensive communication would create a confused perceptual basis. This study indicates that misunderstandings would be an obstacle to closely related perceptions and an obstacle to open communication. The level of feeling understood also correlated positively with the performance 
appraisal, which can be interpreted as the understanding levels are. The less direct and more difficult to attain level of realization did not correlate significantly with the performance appraisal; perhaps it can be inferred that ignorance is truly bliss.

A positive significant correlation of +.2991 found between the perceptual correspondence of issue salience (the relevance and importance of an issue) and the performance appraisal indicates that accurate predictions about how one's co-worker values an issue are important. The assumption behind the SSIPM interpersonal statements regarding how one values an issue, was that values are so fundamentally a part of behavioral tendencies, that they operate in every sphere, including, of course, the work place. Perceptions about values are intended to be tapped in issue salience. The findings suggest that superiors and subordinates with closely corresponding perceptions about how the other values an issue will have a better relationship.

Superior's and subordinate's separate perceptual conjunctions across all issues and levels correspond to the performance appraisal at about the same level, suggesting that neither role provides a perceptual "edge" in the perceptual process.

Between the performance appraisal and elements being 
judged by the superior, there are several factors in this study which are related to that process. Within each superior-subordinate relationship there will be individual differences, but the patterns found in this study indicate that matching perceptions or a lack of them are positively and significantly related to the performance appraisal.

A multitude of factors not named or studied here, no doubt, are a part of the very complex perceptual process. Among the possibilities is the ideal of the rational manager: that performance appraisals predominantly involve a clear and simple process of observing and recording work behaviors without a significant influence of perceptions about other relational issues entering into the process. However, the present investigation supports the theory that the meaning of behavior and experience is mediated through a dynamic perceptual process which is related to the judgment of one individual by another. 
CHAPTER IX

\section{IIMITATIONS AND RECOMMENDATIONS}

\section{Issue Category Survey of Academic Experts}

This section is designed to observe the limitations involved in this study, as well as to offer suggestions for their rectification. Areas to be covered include: test reliability; the performance appraisal; sampling technique; methods and procedures; and conclusion.

The categories of dyadic communication, attitudes and work behaviors are not mutually exclusive, nor is the issue list exhaustive for those categories. The results of the study are limited in that way. The remedy for the problem would be compilation of an exhaustive list of mutually exclusive issues. However, I am not sure if that is possible.

\section{Test Reliability}

The internal consistency of the SSIPM was moderately high, and may be improved by elimination of the four items registering negative correlations and/or experimental inclusion of different issues on the test. This test is just a beginning. Once a high level of reliability is attained, validity should be measured. 
Performance Appraisal

The performance appraisal used in this study is of a very general nature, and served as an external measure of reality. While the SSIPM is a self-report method, the performance appraisal involved one respondent reporting on a partner. It would be more useful to determine the correspondence of relational perceptions with a specific, valid and standardized performance appraisal (if such a thing exists).

\section{Sampling Technique}

The method used in this study did not involve a random sample, and therefore, results may involve a volunteer effect. A random sample would more accurately reflect the universal population of superior-subordinate work dyads. Ideally, several cooperating organizations would be committed to a research effort and responses to questionnaires would be a part of an individual's job were he drawn as a subject. In order to achieve such a level of organizational cooperation, it would be necessary to offer results that would be beneficial to the organization as a whole, while at the same time protecting confidentiality on an individual basis. In addition, it would be informative to sample from groups of superiors and subordinates who, by some other measure, were divided into a group containing people with positive 
working relationships, and a group containing co-workers who were having difficulty with their interpersonal relationships.

\section{Methods and Procedures}

The SSIPM involves a cumbersome test method. Responding to four statements three times from three different perspectives is a tiresome procedure. However, in order to glean information of depth regarding perceptions, there do not appear to be many alternatives. One possibility is to divide the test into three sections, and ask participants to respond to all statements in a section from a certain perspective. For example, from their own perspective in the first section, from their partner's perspective in the second section, and from what they think their partner thinks that they think in the third section. That, too, seems cumbersome, but would perhaps make responding to the statements easier in that continually shifting perspectives would not be necessary.

The procedure for giving test instructions in this study was limited to a letter to the participant. In view of the high number of incomplete, inaccurately completed, and unreturned tests, it seems advisable to provide verbal instructions accompanied by an opportunity to ask questions, as well as written instructions. 


\section{CHAPTER X}

\section{CONCLUSION}

The development of the SSIPM represents an effort to measure the correspondence of dyadic perceptions; the final study represents an effort to learn how those superiorsubordinate perceptions relate to the performance appraisal. The moderately high Cronbach's Alpha produced by the realiability analysis suggests that the instrument has merit. The significant positive relationship established between the SSIPM and the performance appraisal proves that, indeed, there is merit to the idea that perceptions between co-workers are related to how one judges the performance of another. The information here represents but a tiny part of a much larger whole, and the writer is hopeful that it will be useful in further investigations. 


\section{REFERENCES}

Allport, F.H. Theories of perception \& the concept of structure. New York: Wiley, 1955.

Alperson, B.L. A boolean-analysis of interpersonal perception. Human Relations, $1975,28,7,627-652$.

Argyle, M. Social interaction. London: Meuthen, 1969.

Argyris, C. Interpersonal competence and organizational effectiveness. Homewood, Illinois: Dorsey \& Irwin, I962.

Argyris, C. Interpersonal barriers to decision making. Harvard Business Review, 1966, 84-97.

Atkinson, J.S. Motivational determinants of risk-taking behavior. Psychological Review, 1957, 64, 359-372.

Baird, L.S. Self and superior rating of performance: as related to self-esteem and satisfaction with supervision. Academy of Management Journal, 1977, 20, $291-300$.

Bales, R.F. Interaction process analysis. Cambridge, Mass.: Addison Wesley, 1951.

Bateson, G., Weakland, J.H., Haley J. Comments on Haley's "History." In C. Sluzki and D.C. Ransom (Eds.), Double-bind: the foundation of the communication approach to the family. San Francisco: Grune \& stratton, 1976 .

Berlo, David $K$. The process of communication. New York: Holt, Reinhart, and Winston, 1960 .

Brief, A.P. Moderators of the relationship between self and superior evaluations of job performance. Journal of Occupational Psychology, 1977, 50(2), 129-134.

Brooks, W.D. Speech communication. Dubuque, Iowa: Brown 
Brown, M. Values - a necessary but neglected ingredient of motivation. Academy of Management Review, 1976, 15-23.

Cardillo, J.P. Interpersonal perception method (IPM) scoring program in FORTRAN IV. Behavior Research Methods \& Instrumentation, $1978, \overline{10}, 66$.

Cottrell, L.S., Jr. The case study method in prediction. Sociometry, 194la, 4, 358-370.

Dearborn, D.C. \& Simon, H. Selective perception: a note on departmental identification of executives. Sociometry, 1958, 140-144.

Delia, J.G. Some tentative thoughts concerning the study of interpersonal relationships and their development. Western Journal of Speech Communication, 1980, 44, 97-103.

Drory, A. and Ben-Porat, A. Leadership style \& Leniency bias in evaluation of employee performance. Psychological Reports, 1980, 46, 735-739.

Dymond, R.F. A preliminary investigation of the relation of insight and empathy. Journal of Consulting Psychology, $1948,12,228-233$.

Dymond, R.F. A scale for the measurement of empathetic ability. Journal of Consulting Psychology, 1949, $13,127-133$.

Foa, E. and Foa, U. Resource theory of social exchange. In J. Thibaut, J. Spense, and R. Carson (Eds.), Contemporary topics in social Psychology. Morristown, J.J.: General Learning Press, 1976, 99-131.

Gibb, J.R. Defensive communication. Journal of Communication, 1961, XI, No.3, 141-148.

Goldhauber, Gerald M. Organizational communication. Dubuque, Iowa: Brown, 1974 .

Green, C.N. Relationships among role, accuracy, compliance, performance evaluation, and satisfaction within managerial dyads. Academy of Management Journal, 1972 , 15, 205-215.

Grove, T. \& Hays, J. IPALION: A Fortran IV program for comparing interpersonal perceptions in dyads. Behavior Research \& Instrumentation, 1978, 10, 747-749. 
Hall, J. Interpersonal style \& the communication dilemma: II utility of the johari awareness model for genotypic diagnosis. Human Relations, $1975,8,715-736$.

Hastorf, A., Schneider, D.J., \& Polefka, J. Person perception. Reading, Mass.: Addison-Wesley, 1970.

Heneman, H.G. Schwab, D.P. Perspectives on personnel/ human resource management. Homewood, Ill.: Inwin, 1982 .

Heneman , H.G. Comparison of self \& superior ratings of managerial performance. Journal of Applied Psychology, $1974,59,638-642$.

Herzberg, F. One more time: How do you motivate employees? Harvard Business Review, 1968, Jan.-Feb. , 53-62.

Hinde, R.A. Towards understanding relationships. London: Academic Press, 1979 .

Holzbach, R.L. Rater bias in performance ratings. Journal of Applied Psychology, 1978, 63, 579-588.

Homans, C.G. Social behavior:Its elementary form. New York: Harcourt, Brace, 1961 .

Huber, N.A. Superior-subordinate similarity, performance evaluation, and job satisfaction. Dissertation Abstracts International, 1971,31 (7-B), 4380.

Infante, D.A. \& Gordon, W.I. Subordinate \& superior perceptions of self and one another: relations, accuracy and reciprocity of liking. Western Journal of Speech Communication, $1979,43,212-223$.

Jabin, F.M. Superior-subordinate communication: The state of the art. Psychological Bulletin, $1979,86,6,1201-$ 1222 .

Kim, K. II. An empirical investigation of the factors affecting leaders; exchange behavior toward their subordinates. Dissertation Abstracts International, $1978,40,349-\overline{\mathrm{A}}$.

Kolb, D.A., Rubin, I.M., McIntyre, J.M. Organizational psychology: A book of readings. New Jersey: Prentice Hal1, 1971 .

Korman, A.K. A cause of communication failure. Personnel Administration, 1960, 23, 17-21.

Laing, R.D. Self \& others. New York: Pantheon Books, 1969. 
Laing, R.D. The politics of experience. New York: Ballatine Books, 1967.

Laing, R.D. The politics of the family and other essays. New York: Vintage Books, 1972.

Laing, R.D., Phillipson, H. \& Lee, A.R. Interpersonal perception: A theory and a method of research. New York: Springer, 1966.

Landy, F., Barnes, J., Murphy, K.R. Correlates of perceived fairness and accuracy of performance evaluation. Journal of Applied Psychology, 1978, 63, 751-754.

Latham, G. \& Yukl, G.A. A review of research on the application of goal setting in organizations. Academy of Management Review, 1975, 18, 824-845.

Latham, G.P. and Wexley, K.N. Increasing productivity through performance appraisal. Reading, Mass.: 1981.

Levinson, D.J. Seasons of a man's life. New York: Ballatine Books, 1978.

Levinson, H. Management by whose objectives? Harvard Business Review, 1970, July-August, $\overline{125-134}$.

Likert, R. New patterns of management. New York: McGraw-Hill, $19 \overline{61 .}$

Luft, J. Of human interactions. Palo Alto, Calif.: National Press, 1969 .

Maier, N.R.F., Read, W., \& Hooven, J. Breakdowns in bosssubordinate communication. In Foundation For Research on Human Behavior (Eds.,) Communication in organizations: Some new research findings. Ann Arbor, Michigan, 1959.

McCrosky, J.C., Larson, C.E., \& Knapp, M.L. An introduction to interpersonal communication. New Jersey: Prentice Hall, 1971.

MCGregor, D. Leadership and motivation. Cambridge: M.I.T. Press, 1966 .

Mead, G.H. Mind, self and society: From the standpoint of a social behaviorist. Chicago: University of Chicago Press, 1934.

Mellinger, G.D. Interpersonal trust as a factor in communication. Journal of Abnormal Psychology, 1956, 52, 304-309. 
Miller, G., Bosten, F., Roloff, M., Siebold, D. Compliance gaining message strategies; a topology and some findings concerning effects of situational differences. Communication Monographs, 1976, 44, 37-51.

Mitchell, T.R. Motivation: New directions for theory, research and practice. Academy of Management Review, 1982, 7, 80-88.

Moore, M.L. Superior, self and subordinate differences in perceptions of managerial learning times. Personnel Psychology, 1974, 27, 297-305.

Morse, J.J., and Lorsch, J.W. Beyond theory Y. Harvard Business Review, 1970, 61-68.

Nie, N., Hull, C.H., Jenkins, J.G., Steinbrenner, T., Bent, D.H. Statistical package for the social sciences. New York: McGraw-Hill, 1981.

Roach, A.J., and Boyd, L. F. The Personal Data Inventory. In S.R. Bowden, An assessment of the validity of the Marital Satisfaction Inventory. Doctoral Dissertation, Texas A\& M University, 1977, 54.

Rogers, L.E. \& Farace, R.V. Analysis of relational communication in dyads: New measurement procedures. Human Communication Research, 1975, 1, 222-223.

Roloff, M. Interpersonal communications: The social exchange approach. Beverly Hills: Sage, 1981.

Schneider, H.L. Personnel managers look into the $80 \mathrm{~s}$. Personnel Administrator, $1979,24(11), 47-54$.

Senger, J. Manager's perceptions of subordinates' competence as a function of personal value orientations. Academy of Management Journal, 1971, 14(4), 415-425.

Sims, H.P. \& Szilagyi, A.D. Leader reward behavior and subordinate satisfaction and performance. Organizational Behavior \& Human Performance, 1975, 14, 426438 .

Skinner, B.F. Science \& human behavior, New York: MacMillian, 1953.

Smircich, L. \& Chesser, R.J. Superiors' \& subordinates' perceptions of performance: Beyond disagreement. Academy of Management Review, 1981, 24(1), 198-205. 
Smircich, L.M. Authenticity in the superior-subordinate relationship: Its measurement and relationship to committment, involvement, role clarity, influence style \& satisfactions. Dissertation Abstracts International, $1978, \overline{40,} 1,335 \mathrm{~A}$.

Smith, H.R. Perceptions of performance appraisal by superior and subordinate. Dissertation Abstracts International, $1978,39(3-\mathrm{A}), 1378-1379$.

Snyder, M., Decker Tanke, E., Bersheid, E. Social perception $\&$ interpersonal behavior: On the self-fulfilling nature of social stereotypes. Journal of Personality \& Social Psychology, $197 \overline{7,35(9), 656-666 .}$

Stewart, J. Bridges not walls. Menlo Park, Calif.: Addison Wesley, 1973 .

Swenson, C. Interpersonal relations. Illinois: Scott, Foresman, 197 .

Taquiri, R. and Petrullo, L. Person perception and interpersonal behavior. Palo Alto, Calif.: Stanford University Press, 1958.

Tarantino, S.J. Interpersonal perception in male \& female dyads. Perceptual \& Motor Skills, 1973, 36(3), 1046.

Thibaut, J.W. and Kelley, H.H. The Social psychology of groups. New York: Wiley, 1959.

Thornton, G.C. The relationship between supervisory and self-appraisals of executive performance. Personnel Psychology, 1968, 21, 441-456.

Toch, H. and Smith H. C. Social perception: The development of interpersonal impressions. New Jersey: Norstrand! 1968 .

Triandis, H.C. Cognitive similarity \& interpersonal communication in industry. Journal of Applied Psychology, $1959,43,321-326$.

Tucker, R.K., Weaver, R.L., amd Berryman-Fink, C. Research methods in communication. New Jersey: Prentice Hall, 1981 .

Vfenkatramaiah, S.R. and Prasad -K- Parvatheswars. A computer program for interpersonal perception method. Behavior Research Methods \& Instrumentation, 1976, $8(5), 463-464$. 
Verderber, R.F. Communicate! Belmont, Calif., : Wadsworth Publishing, 1980 .

Vroom, V.H. Work \& motivation. New York: Wiley, 1964.

Von Weis, L. Systematic sociology. New York: Wiley, 1932.

Ward, S.A. Rhetorical sensitivity in first-line supervisory relationships: A descriptive \& critical investigation of management literature. Dissertation Abstracts International, 1978, 39(10), 5808-A.

Waxer, E.C. The attraction network \& attitude similarity in a small formal organization: An analysis of dyads. Dissertation Abstracts International, 1978, 39(7), \#4511-A.

Wexley, K.N. Alexander, R., Greenwalt, J.P., and Conch, M.A. Attitudinal congruence \& similarity as related to interpersonal evaluations in manager-subordinate dyads. Academy of Management Journal, 1980, 23(2), $320-330$.

Wilmot, W.W. Dyadic communication. Reading, Mass.: Addison Wesley, 1979 
APPENDICES 
This list of 299 possible test issues was reduced to 40 for the pilot study. The phase in which an issue was eliminated is indicated by numbers to the left of the listing. The various phases consist of elimination based on any one of the following: (1) duplicates or negatives; (2) inappropriate to the work setting; (3) did not elicit a common interpretation, or minimal ambiguity, or refer to a relational issue, or to be monotonic in nature, or to be of relative importance; (4) also appeared on the performance appraisal instrument; (5) final committee scrutiny on relative importance; (6) results of evaluations on understandability and relevancy by personnel professionals. The issues which appeared on the pilot study test are marked by a plus sign to the right of the listing, issues used in the final test are designated with an asterisk.

ability to get along with others absenteeism

accessible

3 accepting of others accurate in work *

3 accepting

3 accepts organizational goals

5 accepts supervision

3 accommodating

3 achievement adaptable * administration advancement advises superior of problems agrees with organization policies agrees with job responsibilities agrees with organizational goals all business articulate analysis of information antagonistic anticipates needs anticipates problems apathetic appreciative appreciates my work +

3 approachable

3 appropriate communication apptitude for the work *

3 assertive

3 attends regularly

3 autonomous 
1 ayoids conversation

3 aware of others

3 careful

candid *

capable

3 cares

3 cheerful

comitted to work *

cormunicates clearly +

3 communicates complete information

6 communicates easily

3 communicates effectively

1 communicates logically

3 communicates frequently

communicates openly + communicates well in groups

3 communicates well with individuals

1 competitive

competent

1 confident

3 confidentiality

3 conforming

3 congenial

5 considerate

6 consistent

3 consults with others

3 contributes

3 content

1 controlling

6 creative

3 credible

1 critical

3 critical thinker

3 considerate

3 delegates

1 defensive

4 dependable

direct $t$

6 does his or her best

1 dominates

3 dynamic

3 discusses problems openly

3 eager

3 effective decision ma

3 efficient

3 emotional

3 empathetic 
encourages others

energetic

enjoys working together

3 enthusiastic

6 equality

3 exercises good judgment

3 expert

3 expresses self effectively

5 expresses support for others

3 expresses thoughts \& feelings

fair +

3 feels like belongs

3 feels valued

3 finds the work rewarding

3 fits into the organization

3 fits the job well

3 follows instructions

3 flexible

3 friendly

3 gets along with others

3 gives constructive criticism

gives feedback +

3 gives full attention

3 gives recognition of others

3 goal oriented

6 good natured

1 gossips

3 growth oriented

6 handles ambiguity well handles conflict well

3 handles criticism well handles stress well * helpful +

3 high expectations

high personal work standards *

1 high goals

1 honest

1 hostile

5 humor

3 independent

1 influenced easily by others

3 influential

3 information timing

3 information amount (completeness)

3 information clarity

3 information appropriateness

3 information accuracy

3 initiates communication 
4 initiative on the job

3 intelligence

3 integrity

3 interrupts

3 interested in his work

3 inquisitive

3 is on time

keeps me informed about business +

1 kind

3 knowledgable

6 knowledge of self

3 leader

learns quickly +

3

likes the oreganization

likes the work

3 likes to work with me

listens +

3 logical

5 loyal

1 maintains confidentiality

6 makes reasonable demands

3 mature

3 meets deadlines

1 motivated to work hard

1 neat

1 negative

3 objective

observant *

3 offers ideas

3 "owns" thoughts \& feelings

3 "owns" mistakes

3 patient

3 persistent

3 personable

3 personal growth

3 personal goals congruent with the job

3 personal values congruent with the job

3 perceptive

3 persuasive

plans effectively +

3 positive

3 practical

3 prioritizes appropriately

3 prompt

productive +

3 punctual 


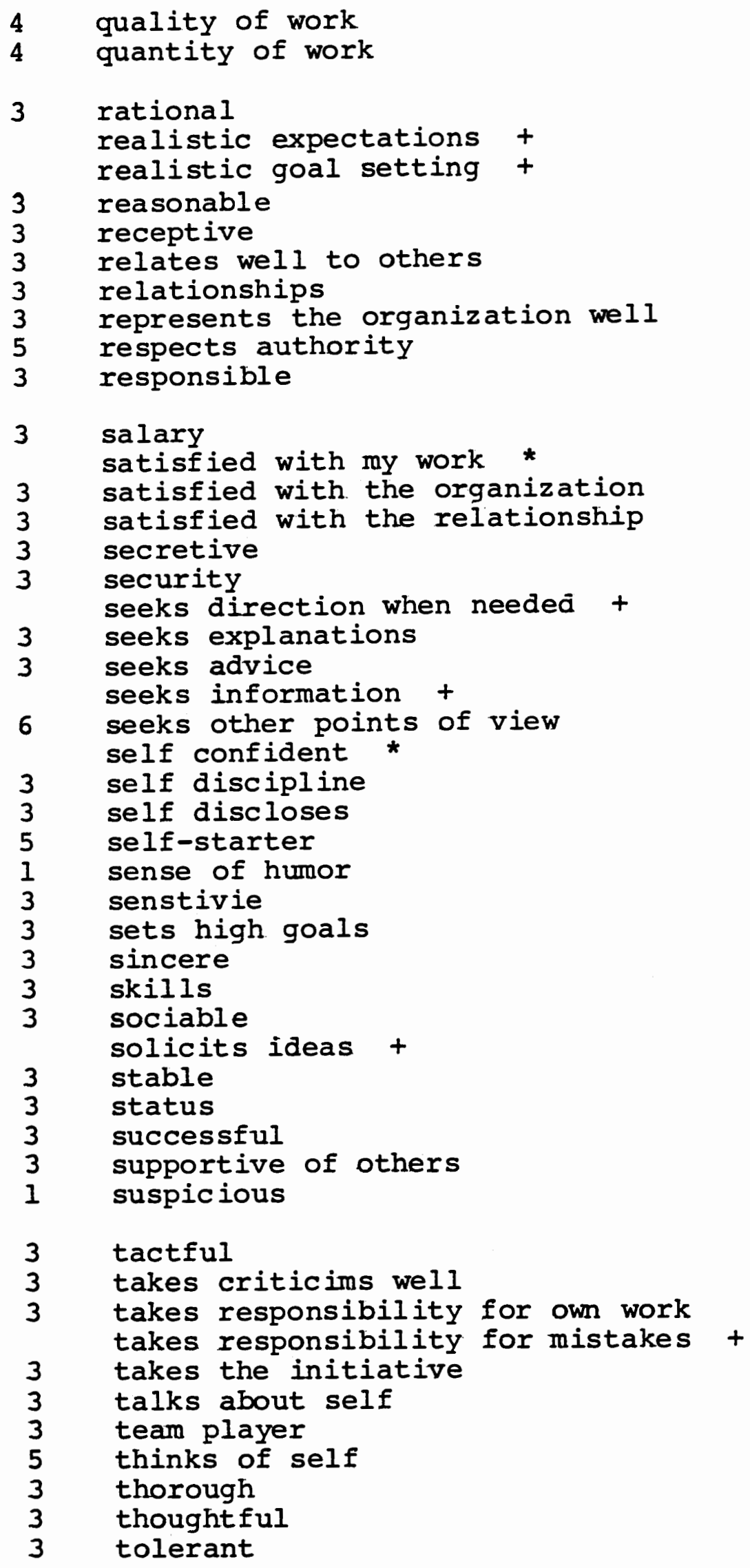


5 understands

uses time wel1 *

well organized +

3

well qualified for the job *

wise

3 working conditions

6 works hard

3 works independently

1 works well with others

IPM ISSUES

1 understands

1 makes mind up for

1 is wrapped up in

3 depends on

1 can't come to terms with

6 takes seriously

1 is disappointed in

1 can't stand

2 takes good care of

1 would like to get away from

1 is afraid of respects +

2 makes center of world

1 is mean with

2 loves

1 tries to outdo

1. fights

1 torments

1 takes responsibility for

1 finds fault with.

5 lets be self

1 couldn't care less about

1 pities

1 doubts

1 makes contradictory demands on

1 gets on nerves

1 mocks is honest with +

1 hates

3 analyzes

1 treats like a machine

1 lets down

1 expects too much of

3 is good to

3 worries about

1 can face up to conflicts

2 is at one with 
1 won't let be

1 blames

3 thinks a lot of

I deceives

1 has lost hope for future

3 likes

1 has a warped view of

3 readily forgives

3 puts on pedestal

1 is bitter toward

1 creates difficulties for

1 belittles

1 is detached from

1 makes a clown of

1 bewilders

3 believes in

1 humiliates

1 is sorry for

1 makes into a puppet

1 spoils

1 owes everything to

1 gets into a false position

6 is kind to 
ORTLAND STATE IVERSITY . box 751 d, oregon 97207 229-3531

PERSONNEL PROFESSIONALS

July 12, 1982

Personnel professional

Organization Name

Address

Dear 8

Thank you for your willingness to resoond to the enclosed questionnaire. Your responses will serve to identify the most important issues to be studied in the superior-subordinate relationship at work. You are one of 18 versonnel professionals whose evaluations will be used in making the final selection of issues for the study.

The results of this questionnaire will be used to develop a second questionnaire which will be given to superior-subordinate nairs. The second questionnaire will determine if the way that suneriors and subordinates view selected issues has an effect on the subordinate's performance anoraisal. These data may be used for a variety of notential anolications in communication and management, e.g., as a diagnostic tool for isolating communication problems.

Thank you for taking time out of your busy schedule to resnond to the questionnaire. Your evaluation of the issues will heln by eliminating the ambiguous issues and identifying the most relevant ones. Please complete the form by Friday, July 23, and return it to me in the enclosed self-addressed envelope.

If you would like to receive an abstract of this study when it is finished, nlease comnlete and return the enclosed post card. If there is a possibility that your organization might allow coonerating superior-subordinate nairs to participate in this study, please indicate that on the post card.

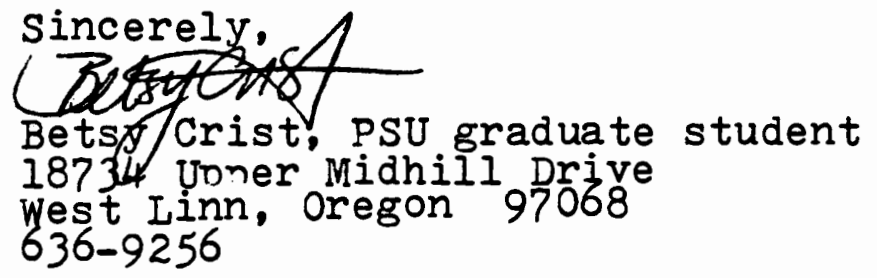


APPENDIX C

SURVEY OF PERSONNEL PROFESSIONALS

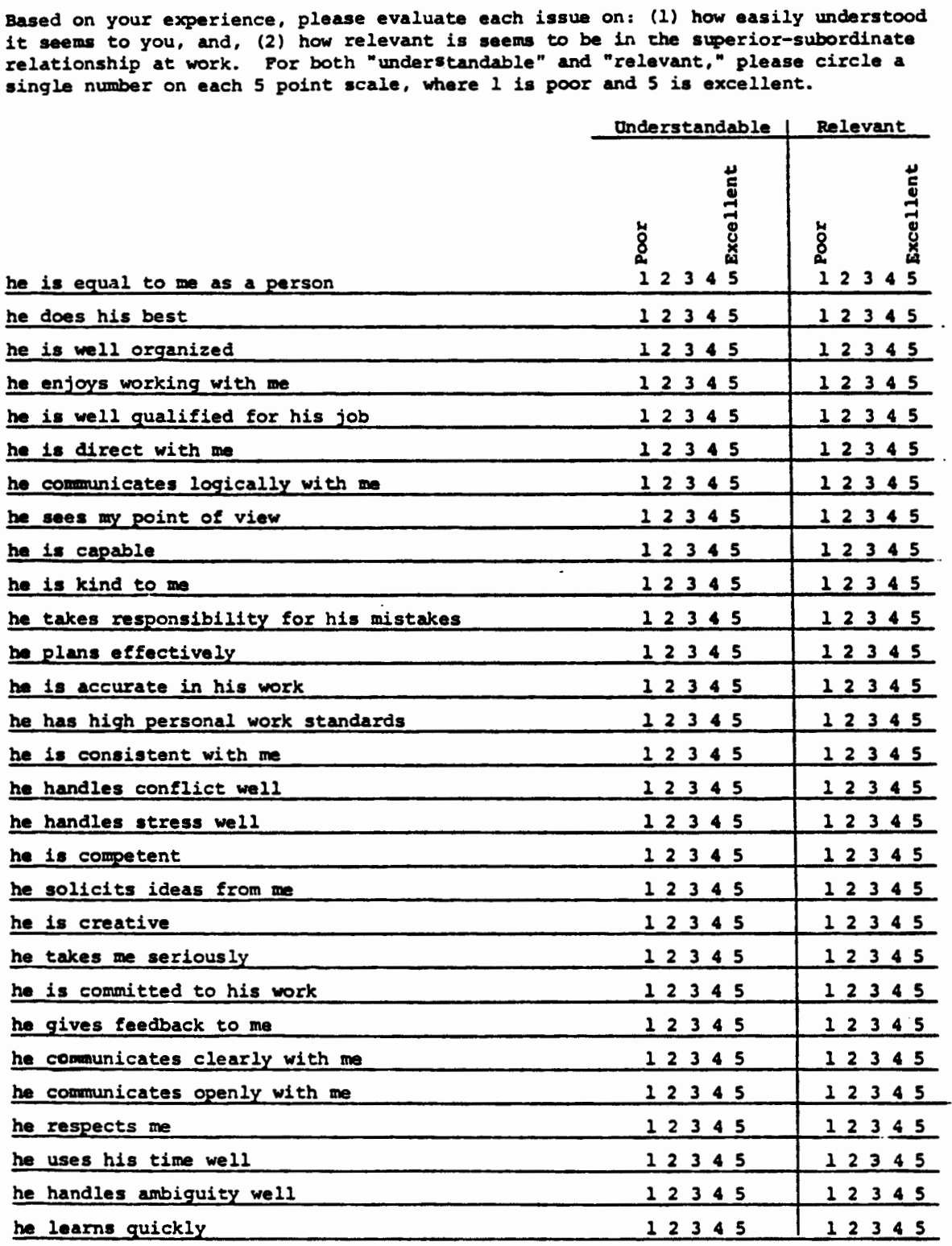






If there are some important issues which have been overlooked in this questionnaire, please add them here: 
ISSUE CATEGORY SURVEY

To:

From: Betsy Crist, 636-9256

I am doing research on three theoretical constructs: attitudes, communication, and work behaviors. I need your expert assistance in determining which of the issues listed below fit into the following categories:

attitude - Manner, disposition, feeling, position with regard to a person or a thing; tendency or orientation, especially of the mind

dyadic communication - any face to face transaction between two people; something imported, interchanged or transmitted.

work - Exertion or effort directed to produce or accomplish something; productive or operative activity.

Please evaluate the issues below based on the above definitions; please check the appropriate column for each. issue, and then return the completed form to by Friday, August 6 .

Thank you very much for your assistance.

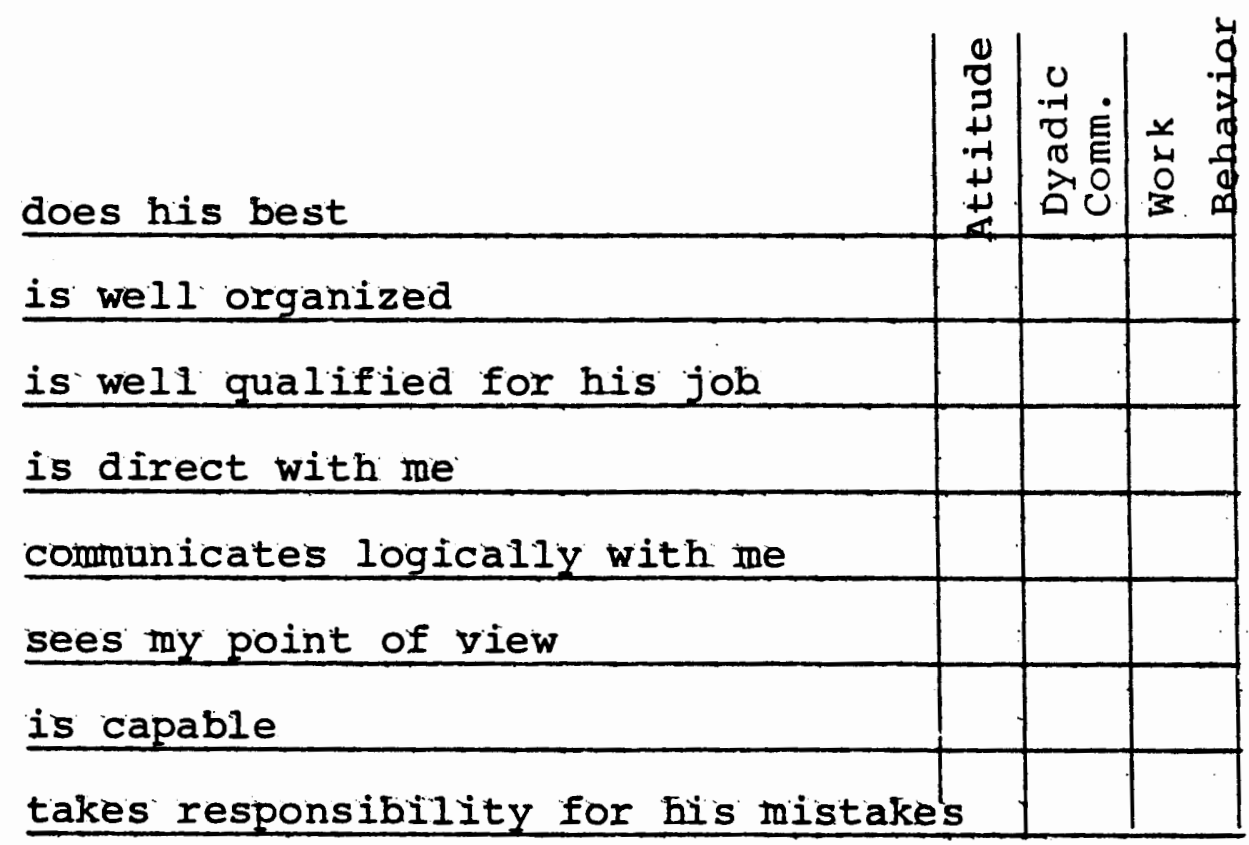


plans effectively

is accurate in his work

has high personal work standard\$

handles conflict well

handles stress well

is competent

solicits ideas from me

is creative

is committed to his work

gives feedback to me

communicates clearly with me

communicates openly with me

respects me

uses his time well

handles ambiguity well

learns quickly

seeks direction when needed

seeks information from me

is honest with me

keeps me informed about business

really listens to me

is candid with me

sets realistic goals

is self confident

is satisfied with my work

is adaptable to changing situations

is fair with me 
is observant

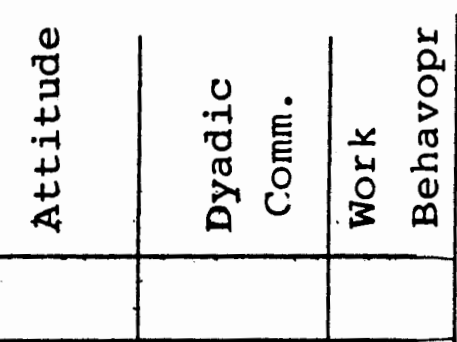

knows what is expected of him at work

has realistic expectations of me

cooperates with me

is productive

makes effective decision

is helpful

has a high aptitude for his work

like his work 


\section{PILOT STUDY TEST}

SUPERVISOR-SUEORDINATE INTERPERSONAL

PERCEPTION METHOD

1. I feel that...

$A$. he is well organized

B. I am well organized

C. he highly values organization

D. I highly value organization

He feels that...

$\mathrm{E}$. he is well organized

F. I am well organized

$G$. he highly values organization

$\mathrm{H}$. I highly value organization

He thinks that I feel that . . .

$I$. he is well organized

J. I am well organized

$\mathrm{K}$. he highly values organization

I. I highly value organization

2. I feel that...
A. he is well qualified for his job
B. I an well qualified for my job
C. he highly values being well qualified for his job
$D$. I highly, value being well qualified for my job

He feels that. .

E. he is well qualified for his job

F. I am well qualified for my job

$G$. he highly values being well qualified for his job

H. I highly value being well qualified for my job

He thinks that I feel that...

I. he is well qualified for his job

$\mathrm{J}$. I an well qualified for my job

$\mathrm{K}$. he highly values being well qualified for his job

I. I highly value being well qualified for my job

3. I feel that...
A. he is direct with me
B. I am direct with him
C. he highly values directness
D. I highly value directness

He feels that. . .

E. he is direct with me

F. I am direct with him

$G$. he highly values directness

H. I highly value directness

He thinks that I feel that...

I. he is direct with me

J. I am direct with him

$\mathrm{K}$. he highly values directness

I. I highiy value directness 
4. I feel that...

A. he communicates logically with me

B. I communicate logically with him

C. he highly values logical communication

D. I highly value logical communication

He feels that. .

E. he comminicates logically with me

F. I communicate logically with him

$G$. he highly values logical communication

$\mathrm{H}$. I highly value logical communication

He thinks that I feel that. .

I. he communicates logically with me

J. I communicate logically with him

$\mathrm{K}$. he highly values logical communication

I. I highly value logical communication

5. I feel that :..

A. he is capable

B. I am capable

C. he highly values being capable

D. I highly value being capable

He feels that...

$E$. he is capable

F. I am capable

G. he highly values being capable

H. I highly value being capable

He thinks that I foel that...

I. he is capable

J. I am capable

$K$. he highly values being capable

I. I highly value being capable

6. I feel that ...

A. he takes responsibility for his mistakes

B. I take responsibility for my mistakes

C. he highly values taking responsibility for one's mistakes

D. I highly value taking responsibility for one's mistakes

He feels that...

E. he takes responsibility for his mistakes

F. I take responsibility for my mistakes

$G$. he highly values taking responsibility for one's mistakes

H. I highly value taking responsibility for one's mistakes

He thinks that I feel that... .

I. he takes responsibility for his mistakes

J. I take responsibility for my mistakes

$K$. he highly values taking responsibility for one's mistakes

I. I highly value taking responsibility for one's mistakes 
7. I feel that ...

A. he plans effectively

B. I plan effectively

C. he highly values effective planning

D. I highly value effective planning

He feels that. . .

E. he plans effectively

F. I plan effectively

$G$. he highly values effective planning

H. I highly value effective planning

He thinks that I feel that.. .

I. he plans effectively

J. I Dlan effectively

$K$. he highly values effective planning

I. I highly value effective planning

8. I feel that . .

A. he is accurate in his work

B. I am accurate in my work

C. he highly values accuracy in work

D. I highly value accuracy in work

He feels that. .

$E$. he is accurate in his work

$\mathrm{P}$. I am accurate in my work

$G$. he highly values accuracy in work

$\mathrm{H}$. I highly value accuracy in work

He thinks that I feel that ...

I. he is accurate in his work

J. I am accurate in my work

$\mathrm{K}$. he highly values accuracy in work

I. I highly value accuracy in work

9. I feel that...
A. he has high personal work standards
B. I have high personal work standards
C. he highly values high personal work standards
D. I highly value high personal work standards

He feels that. .

E. he has high personal work standards

F. I have high personal work standards

$G$. he highly values high personal work standards

H. I highly value high personal work standards

He thinks that I feel that...

I. he has high personal work standards

J. I have high personal work standards

$\mathrm{K}$. he highly values high personal work standards

I. I highly value high personal work standards 
10. I feel that...

A. he handles conflict well

B. I handle conflict well

C. he highly values handling conflict well

D. I highly value handling conflict well

He feels that...

$E$. he handies conflict well

F. I handle conflict well

$G$. he highly values handling conflict well

$\mathrm{H}$. I highly value handling conflict well

He thinks that I feel that . $\cdot$

I. he handles conflict well

$\mathrm{J}$. I handle conflict well

$\mathrm{K}$. he highly values handling conflict well

I. I highly value handling conflict well

11. I feel that $\cdot$.

A. he handies stress well

B. I handle stress well

C. he highly values handling stress well

D. I highly value handing stress well

He feels that...

$E$. he handles stress well

$\mathrm{F}$. I handle stress well

$G$. he highly values handling stress well

H. I highly value handling stress well

He thinks that I feel that...

I. he handles stress well

$\mathrm{J}$. I handle stress well

$\mathrm{K}$. he highly values handling stress well

I. I highly value handling stress well

12. I feel that ...
A. he is competent
B. I am competent
C. he highly values competence
D. I highly value competence

He feels that...

E. he is competent

F. I am competent

$G$. he highly values competence

H. I highly value competence

He thinks that I feel that...

I. he is competent

J. I am competent

$\mathrm{K}$. he highly values competence

I. I highly value competence 
13. I feel that...

A. he solicits ideas from me

B. I solicit ideas from him

C. he highly values soliciting ideas from co-workers

D. I highly value soliciting ideas from co-workers

He feels that. .

E. he solicits ideas from me

$F$. I solicit ideas from him

G. he highly values soliciting ideas from co-workers

$\mathrm{H}$. I highly value soliciting ideas from co-workers

He thinks that I feel that...

I. he solicits ideas from me

$\mathrm{J}$. I solicit ideas from him

$\mathrm{K}$. he highly values soliciting ideas from co-workers

I. I highly value soliciting ideas from co-workers

14. I feel that...

A. he is comnitted to his work

B. I am committed to my work

C. he highly values comittment at work

D. I highly value committment at work

He feels that...

E. he is comitted to his work

F. I am committed to my work

$G$. he highly values committment at work

H. I highly value committment at work

He thinks that I feel that...

I. he is committed to his work

$\mathrm{J}$. I am committed to my work

$K$. he highly values committment at work

I. I highly value committment at work

15. I feel that...

A. he gives feedback to me

B. I give feedback to him

C. he highly values giving feedback

D. I highly value giving feedback

He feels that...

E. he gives feedback to me

F. I give feedback to him

$G$. he highly values giving feedback

H. I highly value giving feedback

He thinks that I feel that . .

I. he gives feedback to me

J. I give feedback to him

K. he highly values giving feedback

I. I highly value giving feedback 
16. I feel that...

A. he communicates clearly with me

B. I communicate clearly with him

C. he highly values clear communication

D. I highly value clear communication

He feels that.. :

E. he communicates clearly with me

F. I communicate clearly with him

$G$. he highly values clear communication

$\mathrm{H}$. I highly value clear communication

He thinks that I feel that...

I. he communicates clearly with me

J. I communicate clearly with him

$K$. he highly values clear communication

I. I highly value clear communication

17. I feel that...

A. he communicates openly with me

B. I communicate openly with him

C. he highly values open communication

D. I highly value open communication

He feels that...

E. he comunicates openly with

F. I communicate openly with him

$G$. he highly values open communication

H. I highly value open communication

He thinks that I feel that ...

I. he communicates openiy with me

J. I communicate openly with him

$\mathrm{K}$. he highly values open communication

I. I highly value open communication

18. I feel that...
A. he respects me
B. I respect $\mathrm{him}$
C. he highly values respect
D. I highly value respect

He feels that...

E. he respects me

F. I respect him

$G$. he highly values respect

H. I highly value respect

He thiniks that I feel that...
I. he respects me
J. I respect him
$\mathrm{K}$. he highly values respect
I. I highly value respect 
19. I feel that...

A. he uses his time well

B. I use my time well

C. he highly values using time well

D. I highly value using time well

He feels that. .

$E$. he uses his time well

F. I use my time well

$G$. he highly values using time well

H. I highly value using time well

He thinks that I feel that...

I. he uses his time well

$\mathrm{J}$. I use my time well

$K$. he highly values using time well

I. I highly value using time well

20. I feel that ...

A. he learns quickly

B. I learn quickly

C. he highly values learning quickly

D. I highly value learning quickly

he feels that...

$E$. he learns quickly

F. I learn quickly

$G$. he highly values learning quickly

H. I highly value learning quickly

He thinks that I feel that...

I. he learns quickly

J. I learn quickly

$K$. he highly values learning quickly

I. I highly value learning quickly

21. I feel that ...

A. he seeks direction when needed

B. - I seek direction when needed

C. he highly values seeking direction when needed

D. I highly value seeking direction when needed

He feels that .. .

E. he seeks direction when needed

F. I seek direction when needed

G. he highly values seeking direction when needed

H. I highly value seeking direction when needed

He thinks that I feel that . .

I. he seeks direction when needed

J. I seek direction when needed

$\mathrm{K}$. he highly values seeking direction when needed

I. I highly value seeking direction when needed 
22. I feel that...

A. he seeks information from me

B. I seek information from him

$\checkmark$. he highly values seeking information

D. I highly value seeking information

He feels that...

E. he seeks information from me

F. I seek information from him

$G$. he highly values seeking information

H. I highly value seeking information

He thinks that I feel that . . .

I. he seeks information from me

$\mathrm{J}$. I seek information from him

$\mathrm{K}$. he highly values seeking information

I. I highly value seeking information

23. I feel that

A. he is honest with me

B. I am honest with him

C. he highly values honesty

D. I highly value honesty

He feels that...

E. he is honest with me

F. I am honest with him

$G$. he highly values honesty

H. I highly value honesty

He thinks that I feel that...

I. he is honest with me

J. I am honest with him

$K$. he highly values honesty

I. I highly value honesty

24. I feel that...

A he keeps me informed about business

B. I keep him informed about business

C. he highly values keeping co-workers informed about business

D. I highly value keeping co-workers informed about business

He feels that...

E. he keeps me informed about business

F. I keep him informed about business

G. he highly values keeping co-workers informed about business

H. I highly value keeping co-workers informed about business

He thinks that I feel that...

I. he keeps me informed about business

J. I keep him informed about business

$\mathrm{K}$. he highly values keeping co-workers informed about business

I. I highly value keeping co-workers informed about business 
25. I feel that...

A. he really listens to me

B. I really listen to him

C. he highly values really listening

D. I highly value really listening

He feels that

E. he realiy listens to me

F. I really listen to him

$G$. he highly values really listening

$H$. I highly value really listening

He thinks that I foel that...

I. he really listens to me

$\mathrm{J}$. I really listen to him

$\mathrm{K}$. he highly values really listening

I. I highly value really listening

26. I feel that...
A. he is candid with me
B. I am candid with him
C. he highly values being candid
D. I highly value being candid

He feels that. . .

$E$. he is candid with me

F. I am candid with him

$G$. he nighly values being candid

H. I highly value being candid

He thinks that I feel that...
I. he is candid with me
J. I am candid with him
$\mathbb{R}$. he highly values being candid
I. I highly value being candid

27. I foel that...
A. he is self confident
B. I am self confident
C. he highly values self confidence
D. I highly value self confidence

He feels that.

E. he is seif confident

F. I am self confident

$G$. he highly values self confidence

H. I highly value self confidence

He thinks that I feel that...
I. he is self confident
J. I am self confident
$\mathrm{K}$. he highly values self confidence
I. I highly value self confidence 
28. I feel that...

A. he is satisfied with my work

B. I am satisfied with his work

C. he highly values my work

D. I highly value his work

He feels that. . .

$E$. he is satisfied with my work

F. I am satisfied with his work

$G$. he highly values my work

H. I highly value his work

He thinks that I feel that...

I. he is satisfied with my work

$\mathrm{J}$. I am satisfied with his work

$\mathrm{K}$. he highly values my work

I. I highly value his work

29. I feel that...

A. he is adaptable to changing situations

B. I am adaptable to changing situations

C. he highly values adaptability to changing situations

J. I highly value adaptability to changing situations'

He feels that...

$E$. he is adaptable to changing situations

F. I am adaptable to changing situations

$G$. he highly values adaptability to changing situations

H. I highly value adaptability to changing situations

He thinks that I feel that ...

I. he is adaptable to changing situations

J. I am adaptable to changing situations

$\mathrm{K}$. he highly values adaptability to changing situations

I. I highly value adaptability to changing situations

30. I feel that ...

A. he is fair with me

B. I am fair with him

C. he highly values fairness

D. I highly value fairness

He feels that...

$E$. he is fair with me

F. I am fair with him

$G$. he highly values fairness

H. I highly value faimess

He thinks that I foel that...

I. he is fair with me

J. I am fair with him

$K$. he highly values fairness

I. I highly value fairness 
31. I feel that...

A. he is observant

B. I am observant

C. he highly values being observant

D. I highly value being observant

He feels that...

$E$. he is observant

F. I am observant

$G$. he highly values being observant

H. I highly value being observant

He thinks that I feel that...

I. he is observant

J. I am observant

K. he highly values being observant

I. I highly value being observant

32. I feel that...

A. he knows what is expected of him at work

B. I know what is expected of me at work

C. he highly values knowing what is expected

D. I highly value knowing what is expected

He feels that...

$\mathrm{E}$. he knows what is expected of him at work

F. I know what is expected of me at work

$G$. he highly values knowing what is expected

H. I highly value knowing what is expected

He thinks that I feel that...

I. he knows what is expected of him at work

J. I know what is expected of me at work

$\pi$. he highly values knowing what is expected

I. I highly value knowing what is expected

33. I feel that...
A. he has realistic expectations of me
B. I have realistic expectations of him
C. he highly values realistic expectations
D. I highly value realistic expectations

He feels that...

E. he has realistic expectations of me

F. I have realistic expectations of $\mathrm{h} / \mathrm{m}$

$G$. he highly values realistic expectations

H. I highly value realistic expectations

He thinks that I feeI that...

I. he has realistic expectations of me

$\mathrm{J}$. I have realistic expectations of him

$K$. he highly values realistic expectations

I. I highly value realistic expectations 
34. I feel that...

A. he cooperates with me

B. I cooperate with him

C. he highly values cooperation

D. I highly value cooperation

He feels that...

E. he cooperates with me

F. I cooperate with him

$G$. he highly values cooperation

H. I highly value cooperation

He thinks that I feel that . . .

I. he cooperates with me

J. I cooperate with him

$\mathrm{K}$. he highly values cooperation

I. I highly value cooperation

35. I feel that. .

A. he is productive

B. I am productive

C. he highly values productiveness

D. I highly value productiveness

He feels that...

E. he is productive

F. I am productive

$G$. he highly values productiveness

H. I highly value productiveness

He thinks that I feel that...

I. he is productive

J. I am productive

$\mathrm{K}$. he highly values productiveness

I. I highly value productiveness

36. I feel that...

A. he makes effective decisions

B. I make effective decisions

C. he highly values effective decision making

D. I highly value effective decision making

He feels that...

פ. he makes effective decisions

F. I make effective decisions

G. he highly values effective decision making

H. I highly value effective decision making

He thinks that I feel that . . .

I. he makes effective decisions

$\mathrm{J}$. I make effective decisions

K. he highly values effective decision making

I. I highly value effective decision making 
37. I feel that $\ldots$.

A. he is helpful

B. I am helpful

C. he highly values helpfulness

D. I highly value helpfulness

He feels that...

E. he is helpful

F. I am helpful

$G$. he highly values helpfulness

H. I highly value helpfulness

He thinks that I feel that...

I. he is helpful

J. I am helpful

$K$. he highly values helpfulness

I. I highly value helpfulness

38. I feel that...
A. he appreciates my work
B. I appreciate his work
$C$. he highly values appreciation
D. I highly value appreciation

He feels that. .

5. he appreciates my work

F. I appreciate his work

$G$. he highly values appreciation

H. I highly value appreciation

He thinks that I feel that...

I. he appreciates my work

J. I appreciate his work

$K$. he highly values appreciation

I. I highly value appreciation

39. I feel that . .

A. he has a high aptitude for his work

B. - I have a high aptitude for my work

C. he highly values having a high aptitude for the work

D. I highly value having a high aptitude for the work

He feels that...

E. he has a high aptitude for his work

F. I have a high aptitude for my work

$G$. he highly values having a high aptitude for the work

H. I highly value having a high aptitude for the work

He thinks that I feel that...

I. he has a high aptitude for his work

$\mathrm{J}$. I have a high aptitude for my work

$K$. he highly values having a high aptitude for the work

I. I highly value having a high aptitude for the work 
40. I feel that.

A. he likes his work

B. I like my work

C. he highly values liking his work

D. I highly value liking my work

He feels that...

E. he likes nis work

F. I like my work

$G$. he highly values liking his work

H. I highly value liking my work

He thinks that I feel that.. •

I. he likes his work

J. I like my work

K. he highly values liking his work

I. I highly value liking my work 


\title{
APPENDIX F
}

\author{
POPTLAND STATE UNIVERSIT
}

APPLICA.TION FOR REVIEH OF FISLARCH PROJECT

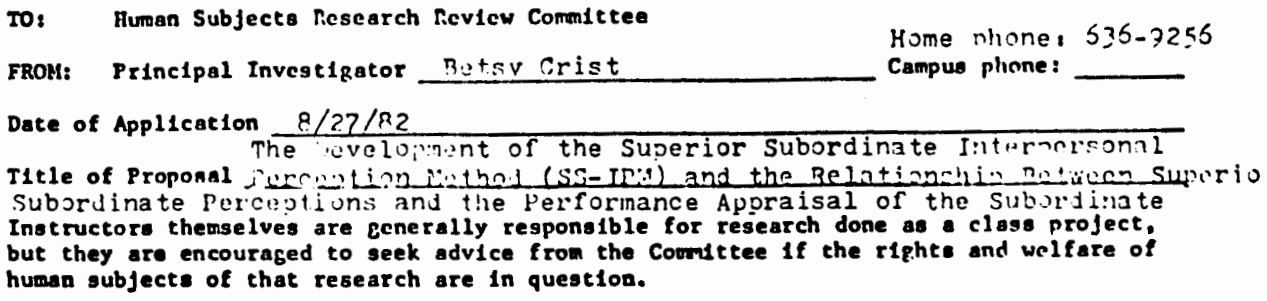

Applicatione for research grants or training proprans that propose to use human subjecte for revearch purposes must be accompanied by atatement algned by the principal Inveat1gator, and by the University authorized official. This required statement asserts that the proposed Investication has had prior review by an Independent University cownittee, and that the procedures to be used (1) protect the rights and welfare of the subjecte, and (2) provide for the securing of informed consent from thes, and, if persons under the ape of 18 are to particlpate as subjects, the informed consent of parento or guardiane. Anawer to the following questions will provide the necessary Inforwation for the Univeralty conittee and the eranting agency. Three (3) coples of the APPLICATIOA FOR COMITTEE REVIEN ITST BE RECEIVED AT LEAST 10 (ten) WORSING DAYS REPCRE Air SUBrisstoi DATE OR OTHER DEADLINE. Th1s application W1II be kept on fIle at the offlce of Graduate Studics and Resesrch.

The ltems belou are to be coupleted by the Project Director (chief Invest1pator).

I. Profect title and prospectue (300 words or less). State thether the prooosed research would be conducted persuant to contract or grant and identify the contractor of grantor agency. 'If proposal lo result of a Request for Propoeal. glve RTP number.

The proposed research is pursuant to a master of science in speech communication. The problem to be studied is the relationship between superior-subordinate perceptions and the performance appraisal of the subordinate by the superior.

II. Subject Recrultment. Describe subject recrultment procedures for all subjects used in the etudy.

Subjects will be superior-subordinate pairs within local business organizations and places of public employment. Please see the attached particlpant recruitment letter which was distributed to employees at Eastmoreland General Hospital for the pilot gtudy taking place in Sept. A similar letter will be used to seek participants in other organizations for the flnal research in October. Nilling participants contact an identifled person in the personnel department. Participants will be presented with a consent form prifor to cesponding to the supervisor- 
Application for Use of Human Subject:

Page 2

III. Informed, voluntary consent in writing. Describe subject sainple(s) and manner In which consent was obtalned for eacli approprlate catcrory.

A. Adult Subjects (Includes persons 18 years of ape and over). Subject consent required.

Describe who/where/when/how

iho, adult emoloyees of local business orranizations

Where, at the subject's place of employment

ihen: during, work hours at the place of ivork

How: rubjects will be oresented with a consent form orior to particisating in the study

B. Chlld Subjecte (1ncludes all persone under 18). Parent/Guardian consent required. (Subjects over eevea years of age nuat give their consent as we11.)

Describe who/where/when/hov

$N / A$

C. Institutionalized Subjecta. Subject conaent and consent of appropriate, responelble Inetitutional ataf person (e.g., prison paychiatrist) reculred.

Describe who/where/when/how

$\mathbf{N} / \mathbf{A}$

IV. F1rst-person ocenarto (short paragraph presenting participation expertence frow subject' point of VIew; e.8.8 "I was seated at table by the Invectigator and.." ").

After agreeing to particlpate in this study and signing a consent forn I was given the SS-IPM and asked to respond "yes" or "no" to each sta" ment by filling in appronriate boxes on the computer answer pages. T? test was delivered by the investigator, and $I$ was asked to respond at convenience within the perlod of two working days. When my answers we recorded I sealed them in an envelope and delivered it to the desif,n. oerson within my orfanization. 
Appilication for lise of Eumno Subject:

race 3

v. Potent1al rioke and saferunrds.

A. Descrtbe rloks (physical, psycholortcal, social, legal or other).

There are no risks to study participants.

B. Explain procedures and precautions safequarifing acainst riske noted above.

N/A

vI. Fotential benefits of the proposed lnvestigation (brief outline).

The development of an instrument which may be used to facilitate communication between superiors and subordinates at work.

vII. Records and distribution. In the event that information fror the Investgation will be kept on f1le or distributed (published, copled), what proviolons for aubject anonyatity have been adopted?

Individual names are not recorded or used in any way. Code numbers are given to forms and response pages to keep approprtate information toge ther.

i1. lionitoring system. [1ther: $A$ Indicate compliance with ycur departmental system for nonitoring humon subjects research ectivitles or B) Describe your orn monftoring eystem for this Investication (only the portion pertaininp to use of hunan oubjects).

Deemed unnecessary as per departmental monitoring system.

Checked by:

Strnature of Dept. Chalrperson or Lfent

Date

Campus Thone:
Subritted by:

S1gnature of Project DIrector

Date Dept.

Caupug/fome Thones

Carpue "all cote: 
BUMAN SUBTECIS RESEARCB REVIEN COMATTTEE

towatex 1982-83

October 12, 1982

$\operatorname{sos}^{2}$

TO:

Betsy Cr1st

FROM:

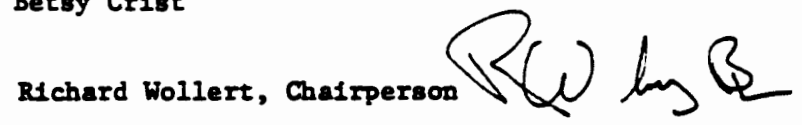

In accordance with your request, the Bumen Subjects Research Review Comittee

has reviewed your proposal entitled, Development of the Superior Subordinate Inter-

personal Perception Method and the Relationship Between Superior Subordinate Percept1ons...

for compliance with DHEW pollcies and regulations on the protection of himm subjects.

The committee is satisfied that your provisions for protecting the Fights and velfare of all subjects participating in the research are adequate and therefore the profect is approved. Any conditions relative to this approval are noted below.

Cond1tions:

If the total time combitment 182 hours as seems to be implied on the Inftial letter the informed consent form should say 2 instead of 1 hour.

snother problem is the post-hoc nature of this reviex. The (P1lot) data have apparentiy already been collected.

cc: Office of Graduate Studies and Research 
Code\#

PERSONAL DATA INVENTORY

AGE:

$20-29$

$30-39$

$40-49$

$50-59$

60 and over

OCCUPATION:

NO. YEARS IN PRESENT POSITION:

NO. YEARS WORKED WITH TEST PARTNER:

MY FRIENDS WHO RNOW WOULD RATE MY RELATIONSHIP WITH MY TEST PARTNER AS :

Poor

Fair

Average

Good

Excellent
YOUR EDUCATION (highest level)

Did not finish high school

High school graduate

Some college

Bachelor's degree

Master's degree

Doctoral or other professional degree

ALI THINGS CONSIDERED, MY SATISFACTION WITH MY JOB RIGET NOW:

Extremely satisfied

Very satisfied

Satisfied

Somewhat dissatisfied

Very dissatisfied 
PILOT STUDY RECRUITMENT LETTER

RTLAND STATE VERSITY box 751 d, oregon 97207 229-3531

Greetings:

I am a Portland State University graduate student doing a study which I hope will interest you. I need your help.

I am seeking supervisor-subordinate pairs who have worked together for a least one year, have daily contact and who are willing to individually respond to a questionnaire - twice, two weeks apart. The purpose of a test and a re-test is to determine the reliability of the statements on the questionnaire. For each test response the time commitment will. be about one hour.

Should you decide to participate, you will be aiding in the development of an instrument designed to compare the perceptions of two people regarding important issues in their work relationship. I am trying to learn if the supervisor-subordinate relationship affects the subordinate's performance appraisal.

Will you help? All responses will be confidential; questionnaires will be coded and responses will be seen only by me. If you and your co-worker are willing, please give your names to Judy Clark by Wednesday, September lst.

If you agree to participate, the first questionnaire will be delivered to you on Tuesday, September 7th. You will have three days to complete the test and I will collect your responses on Thursday, September $9 t h$, late in the afternoon. The second questionnaire will be delivered to you on Tuesday, September 2lst, and it should be completed two weeks from the day you originally took the test, if at all possible. I will return on Thursday, September 23, late in the afternoon, to collect the final responses.

Completion of both the test and the re-test is critical to this portion of the study, so if you agree to participate, remember that responding to both tests is very important. I'm counting on you.

Thank you for your time and thought in consideration of this request.

Sincerely,

Betsy Crist 
INSTRUCTION LETTER TO SUPERIORS:

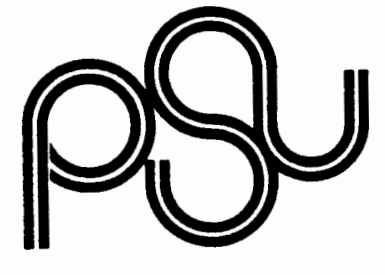

September 7, 1982

DRTLAND STATE IVERSITY box 751 d, oregon

97207

'229-3531

college of and letters artment of nunication

\section{Dear Participant:}

The Supervisor-Subordinate Interpersonal Perception Method (SSIPM) is designed to measure the accuracy or inaccurcy of your own and your co-worker's perceptions on a key range of issues related to your working relationship. The test is taken individually, and all responses will be confidential; code numbers will serve to keep appropriate information together.

You are asked to respond to the statements on the questionnaire in the context of your work environment, and on the basis of your work relationship with your test partner. Each statement should be thought of in a general sense; as you would judge things on the whole. For example, "he does his best" may remind you of a recent incident where you did not feel that your co-worker really did his best. If this was not his usual practice, and he generally does his best, please respond by affirming that he does his best, and disregard the unusual event.

You are being asked to respond to each statement from three perspectives: your own, what you think your coworker feels, and what you think that he thinks that you feel. It may seem difficult to you, but people do think this way, although often not consciously or continuously. I am asking you to think in this manner.

Please read each statement as a full sentence, for example, "I feel he does his best," - think of it as it applies to you and your test partner generally, and respond by filling in the appropriate spot on your computer page. Move through thee questionnaire as quickly as possible, marking your first impression response.

DIRECTIONS FOR SCORING THE SUPERVISOR-SUBORDINATE INTERPERSONAL PERCEPTION METHOD:

1) Do not consult with your test partner about this until after you have finished the re-test in two weeks.

2) Please do not write on the computer forms except when 
shading in the answer spaces.

3) Use a \#2 pencil and press hard, completely filling in the rectangular space provided for responses on the computer forms.

4) Please respond to each statement: unanswered statements make it iropossible to interprt all the following items.

5) Please note that there are two computer answer forms which have elongated boxes numbered 1-24 horizontally. Theree are 40 issues to respond to in all. Mark the first 24 on page 1 of the computer forms, and mark your responses to issues $25-40$ on page 2. Each issue has 12 statements to which you should respond. Shade " $y$ " for yes, or " $n$ " for no, going vertically from letter $A$ to $I$.

GENERAI INSTRUCTIONS:

1) Please sign the informed consent form.

2) Supervisors: please respond to the enclosed performance appraisal form prior to doing the supervisorSubordinate Interpersonal Perception Method.

3) After you have completed the performance appraisal form and responded to all the statements on the Supervisor-Subordinate Interpersonal Perception Method, please complete the Personal Data Inventory.

4L Please enclose the test, the computer answer pages, the informed consent form, the performance appraisal form and the personal data form in the envelope provided; seal the envelope and give it to Kay Larson.

51 Please have your answers recorded, sealed and delivered by 5 p.m. on Thursday, September 9th; I will come to Eastmoreland General Hospital to collect the forms at that time. I will return at 8 a.m. on Tuesday, September 21 st to deliver the retest. Please pick up your retest from Personnel and try to take the retest two weeks from the date of your original test completion. I will return at 5 p.m. on Thursday, September 23 to collect all final responses.

The purpose of the test and retest is to determine the reliability of the issues being used on the test. Individual responses will be scored, showing where your perceptions do or do not match your test partner's. The 
purpose of this study is to develop a tool which can be used to help people improve their on-the-job communication. A general summary will be sent to you when this research is complete.

Thank you for your time, thought and effort; your responses are critical to this research.

\section{Sincerely, \\ Betsy Crist}

Encl: $\quad 1$ Supervisor-Subordinate Interpersonal Perception Method, 2 computer answer pages, 1. Personal Data Inventory, 1 Performance Appraisal, and 1 informed consent form. 
shading in the answer spaces.

3) Use a \#2 pencil and press hard, completely filling in the rectangular space provided for responses on the computer forms.

4) Please respond to each statement; unanswered statements make it impossible to interpret all the following items.

51 Please note that there are two computer answer forms which have elongated boxes numbered 1-24 horizontally. There are 40 issues to respond to in all. Mark the first 24 on page 1 of the computer forms, and mark your responses to issues 25-40 on page 2. Each issue has 12 statements to which you should respond. Shade " $y$ " for yes, or " $n$ " for no, going vertically from letter $A$ to $L$.

GENERAL INSTRUCTIONS:

1) Please sign the informed consent form.

2) Please respond to all statements on the SupervisorSubordinate Interpersonal Perception Method, and then complete the Personal Data Inventory.

3) Please enclose the test, the computer answer pages, the informed consent form, and the personal data form in the envelope provided; seal the envelope and give it to Kay Larson.

42 Please have your answers recorded, sealed and deliverered by 5 p.m. on Thursday, Septembr 9th; I will come to Eastmoreland General Hospital to collect the forms at that time. I will return at 8 a:m. on Tuesday, September 2lst, to deliver the retest. Please pick up your retest from Personnel. Please do the retest two weeks from the aate of your original test completion if possible. I will return at $5 \mathrm{p} . \mathrm{m}$. on Thursady. September 23 to collect the final responses from Kay Larson.

The purpose of the test and retest is to determine the reliability of the issues being used on the test. Individual responses will be scored, showing where your perceptions do or do not match your test partner's. The purpose of this study is to develop a tool which can be used to help people improve their on-the-job communication. A general sumary will be sent to you when this research is complete. 
Thank you for your time, thought and effort; your responses are critical to this research.

\author{
Sincerely, \\ Betsy Crist
}

Encl: $\quad 1$ Supervisor-subordinate Interpersonal Perception Method, 2 computer answer pages, 1 Personal Data Inventory, and 1 Informed Consent. 
INFORMED CONSENT

I, herebeby agree to serve as a subject in the investigation of the supervisorsubordinate work relationship conducted by Betsy Crist. I understand that the study involves recording my responses of "yes or "no" to statements that I read. I understand that this process will take approximately twenty minutes.

It has been explained to me by letter that the purpose of the study is to learn about how supervisor-subordinate perceptions might affect the subordinate's performance appraisal. I may not receive any direct benefit from participation in this study, but my participation may help to increase knowlede which may benefit others in the future.

I have been assured that all information I give will be kept confidential and that the identity of all subjects will remain anonymous.

I understand that I am free to withdraw from participation in this study at any time without jeopardizing my relationship with Portland State University.

I have read and understand the foregoing information. Date Signature 
If you experience problems that are the result of your participation in this study, please contact Victor C. Dahl, Office of Graduate Studies and Research, 105 Neuberger Hall, Portland State University, 229-3423. 


\section{FINAL STUDY}

SUPERVISOR-SUBORDINATE INTERPERSONAL

\section{PERCEPTION METHOD}

1. I feel that. -
A. she is well qualified for her job
B. I am well qualified for my job
C. she highly values being well qualified for her job
D. I highly value being well qualified for my job

She feels that . .

E. she is weil qualified for her job

F. I am well qualified for my job

G. she highly values being well qualified for her job

H. I highly value being well qualified for my job

She thinks that I feel that . .

I. she is well qualified for her job

J. I am well qualified for my job

$K$. she highly values being well qualified for her job

L. I highly value being well qualified for my job

2. I feel that. . .

A. she is capable

B. I am capable

C. she highly values being capable

D. I highly value being capable

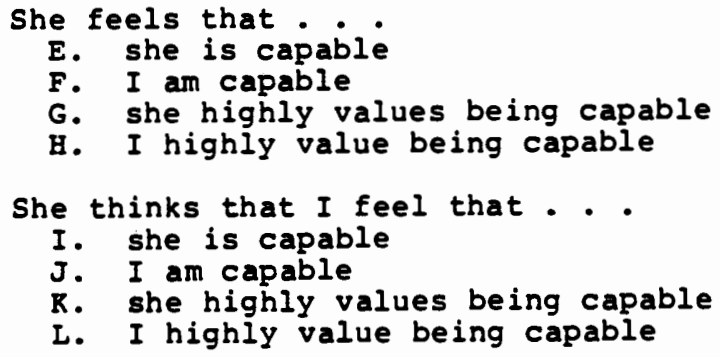

3. I feel that...

A. she is accurate in her work

B. I am accurate in my work

C. she highly values accuracy in work

D. I highly value accuracy in work

She feels that. .

$E$. she is accurate in her work

F. I am accurate in my work

$G$. she highly values accuracy in work

B. I highly value accuracy in work

She thinks that I feel that...

I. she is accurate in her work

$\mathrm{J}$. I am accurate in my work

$\mathrm{K}$. she highly values accuracy in work

L. I highly value accuracy in work 
4. I feel that...

A. she has high personal work standards

B. I $h$ ve high personal work standards

C. She highly values high personal work standards

D. I highly value high personal work standards

She feels that...

E. She has high personal work standards

$F$. I have high personal work standards

G. She highly values high personal work standards

H. I highly value high personal work standards

She thinks that I feel that...

I. she has high personal work standards

J. I have high personal work standards

$R$. She hiahly values high personal work standards

L. I hiahly value high personal work standards

5. I feel that . .

A. she handies conflict well

B. I handle conflict well

C. she hiahly values handling conflict well

D. I highlv value handling conflict well

She feels that...

E. She handles conflict well

F. I handle conflict well

G. She highly values handling conflict well

H. I highly value handing conflict well

She thinks that I feel that...

I. she handles conflict well

J. I handle conflict well

$R$. she hiahly values handing conflict well

I. I highly value handing conflict well

6. I feel that...

A. she is competent

B. I am competent

C. she highly values competence

D. I highly value competence

She feels that...

E. she is competent

F. I am competent

G. She highly values competence

H. I highly value competence

She thinks that I feel that...

I. she is competent

J. I am competent

$\mathrm{R}$. She highly values competence

L. I highly value competence 
7. I feel that...

A. she is committed to her work

B. I am committed to my work

C. She highly values committment at work

D. I highly value committment at work

She feels that...

E. she is committed to her work

F. I am committed to my work

G. she highly values committment to work

H. I highly value committment to work

She thinks that I feel that...

I. She is committed to her work

J. I am committed to my work

$R$. she highly values committment at work

L. I highly value committment at work

8. I feel that...

A. she uses her time well

B. I use my time well

C. she highly values using time well

D. I highly value using time well

She feels that...

E. She uses her time well

F. I use my time well

G. She highly values using her time well

H. I highly value using my time well

She thinks that I feel that...

I. She uses her time well

$\mathrm{J}$. I use my time well

$\mathrm{K}$. she highly values using time well

L. I highly value using time well

9. I feel that: . .
A. she is candid with me
B. I am candid with her
C. she highly values being candid
D. I highly value being candid

She feels that...

E. she is candid with me

F. I am candid with her

$G$. she highly values being candid

H. I highly value being candid

She thinks that I feel that...

I. she is candid with me

J. I am candid with her

$R$. she highly values being candid

L. I highly value being candid 
10. I feel that...
A. she is self confident
B. I am self confident
C. She highly values self confidence
D. I highly value self confidence

She feels that . .

E. she is seif confident

F. I am self confident

G. she highly values self confidence

H. I highly value self confidence

She thinks that I feel that...

I. she is self confident

J. I am self confident

$R$. she highly values self confidence

I. I highly value self confidence

11. I feel that...

A. she is satisfied with my work

B. I am satisfied with her work

C. She highly values my work

D. I highly value her work

She feels that. . .

E. She is satisfied with my work

F. I am satisfied with her work

$G$. She highly values my work

H. I highly value her work

She thinks that I feel that...

I. she is satisfied with my work

J. I am satisfied with her work

$R$. she highly values my work

I. I highly value her work

12. I feel that...
A. She is adaptable to changing situations
B. I am adaptable to changing situations
C. she highly values adaptability to changing situations
D. I highly value adaptability to changing situations

She feels that...

E. She is adaptable to changing situations

F. I am adaptable to changing situations

$G$. She highly values adaptability to changing situations

H. I highly value adaptability to changing situations

She thinks that I feel that...

I. she is adaptable to changing situations

$\mathrm{J}$. I am adaptable to changing situations

R. she highly values adaptability to changing situations

L. I highly value adaptability to changing situations 
13. I feel that . .
A. she is observant
B. I am observant
C. she highly values being observant
D. I highly value being observant

She feels that...

E. she is observant

F. I am observant

G. she highly values being observant

H. I highly value being observant

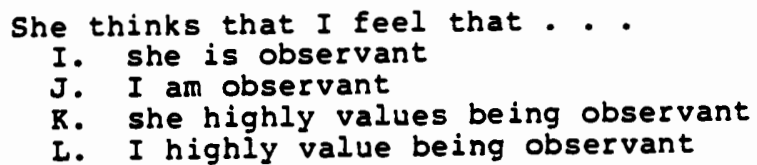

14. I feel that...
A. she makes effective decisions
B. I make effective decisions
C. she highly values effective decision making
D. I highly value effective decision making

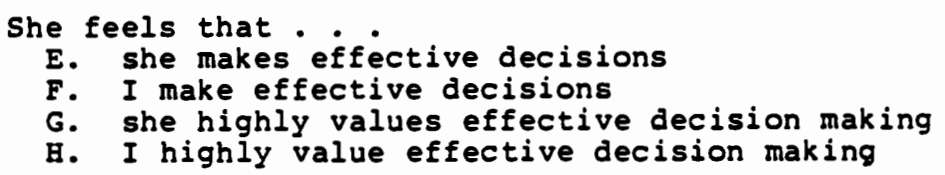

She thinks that I feel that...

I. she makes effective decisions

J. I make effective decisions

R. she highly values effective decision making

I. I highly value effective decision making

15. I feel that...

A. she has a high aptitude for her work

B. I have a high aptitude for my work

C. she highly values having a high aptitude for the work

D. I highly value having a high aptitude for the work

She feels that. . .

E. she has a high aptitude for her work

F. I have a high aptitude for my work

G. she highly values having a high aptitude for the work

H. I highly value having a high aptitude for the work

She thinks that I feel that...

I. she has a high aptitude for her work

J. I have a high aptitude for my work

R. she highly values having a high aptitude for the work

I. I highly value having a high aptitude for the work 
16. I feel that...

A. she likes her work

B. I like my work

C. she highly values liking her work

D. I highly value liking my work

She feels that. .

E. she likes her work

F. I like my work

G. she highly values liking her work

H. I highly value liking my work

She thinks that I feel that. . .

I. she likes her work

J. I like my work

K. she highly values liking her work

I. I highly value liking my work 
Dear Supervisor:

This portion of the study involves the rating of your subordinate test partner on his or her work performance. There will be no rating of the supervior by the subordinate.

Based on your observation of the person you are evaluating, please rate him or her on each aspect listed by circling a single number on the five point scale, where 1 is poor and 5 is excellent. Please complete this form prior to taking the Supervisor-Subordinate Interpersonal Perception Method. Please seal it in the envelope provided together with the computer response page, the test, the signed consent form, and the personal data inventory form.

\section{PERFORMANCE APPRAISAL}

Quality of Work

Quantity of Work

Dependability

Ability to get along with others

Initiative on the job

Overall Performance
4
$\circ$
$\circ$
$\circ$

$\begin{array}{lllll}1 & 2 & 3 & 4 & 5\end{array}$

$\begin{array}{lllll}1 & 2 & 3 & 4 & 5\end{array}$

$\begin{array}{lllll}1 & 2 & 3 & 4 & 5\end{array}$

$\begin{array}{lllll}1 & 2 & 3 & 4 & 5\end{array}$

$\begin{array}{lllll}1 & 2 & 3 & 4 & 5\end{array}$

$\begin{array}{lllll}1 & 2 & 3 & 4 & 5\end{array}$ 
September 16, 1982

ORTLAND VERSITY o. box 751 d, oregon 97207 229-3531

\section{Greetings:}

I am a Portland State University graduate student doing a study which I hope will interest you. I need your help.

I am seeking superyisor-subordinate pairs who have worked together for a least one year, have daily contact, and who are willing to individually respond to a questionnaire. The time commitment will be about twenty minutes.

Should you decide to participate, you will be aiding in the development of an instrument designed to compare the perceptions of two people regarding important issues in their work relationship. I am trying to learn if the supervisor-subordinate relationship affects the subordinate's performance appraisal. Participants will not receive any direct benefit from participation in this study, but their efforts will help increase knowledge which may benefit others in the future. The study will result in a tool which can be used to improve on-the-job communication. A general summary of results will be provided to all participants.

Will you help? All responses will be confidential; questionnaires will be coded and responses will be seen only by me. If you and a supervisor or subordinate co-worker are willing, please give your names to by Wednesday, september 22. Individuals may respond to the test only once.

If you agree to participate, the questionnaire will be delivered to you on Monday, October 4th. I am requesting that you complete the test sometime during that work week before noon on Friday, October 8th. I will come to collect the test responses at that time. Please remember that if you do agree to participate, I will be counting on your test completion.

Thank you for your time and thought in consideration of this request.

Sincerely,

Betsy Crist 
INSTRUCTION LETTER TO SUBORDINATES:

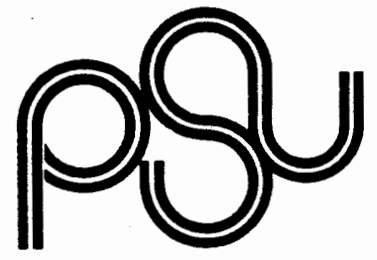

FINAL STUDY

October 4, 1282

ORTLAND

STATE IVERSITY . box 751 d, oregon 97207 229-3531

Dear Participant:

The Supervisor-Subordinate Interpersonal Perception Method (SSIPM) is designed to measure the accuracy or inaccuracy of your own and your co-worker's perceptions on a key range of issues related to your working relationship. The test is taken individually, and all responses will be confidential; code numbers will serve to keep appropriate information together.

You are asked to respond to the statements on the questionnaire in the context of your work environment, and on the basis of your work relationship with your test partner. Each statement should be thought of in a general sense; as you would judge things on the whole. For example, "he does his best" may remind you of a recent incident where you did not feel that your co-worker really did his best. If this was not his usual practice, and he generally does his best, please respond by affirming that he does his best, and disregard the unusual event.

You are being asked to respond to each statement from three perspectives: your own, what you think your co-worker feels, and what you think that he thinks that you feel. It may seem difficult to you, but people do think this way although often not consciously or continuously. I am asking you to think in this manner.

Please read each statement as a full sentence, for example, "I feel he does his best," - think of it as it applies to you and your test partner generally, and respond by filling in the appropriate spot on your computer page. Move through the questionnaire as quickly as possible, marking your first impression response.

DIRECTIONS FOR SCORING THE SUPERVISOR-SUBORDINATE INTERPERSONAL PERCEPTION METHOD:

12 Please do not discuss this test with your test partner until after both of you have finished testing.

2) Please do not write on the computer form except when shading in the answer spaces. 
3) Use a \#2 pencil and press hard, completely filling in the rectangular space provided for responses on the computer form.

4) Please respond to each statement; unanswered statements make it impossible to interpret all the following items.

5) Please note that there is a computer answer form which has elongated boxes numbered 1-24 horizontally. There are 18 test items, and each item has 12 statements to which you should respond. Shade " $y$ " for yes, or " $n$ " for no, going vertically from letter $A$ to $L$ on the computer answer form.

GENERAL INSTRUCTIONS:

1) Please sign the informed consent form.

2I Please respond to all statements on the SupervisorSubordinate Interpersonal Perception Method, and then complete the Personal Data Inventory.

3) Please enclose the test, the computer answer page, the informed consent form, and the personal data form in the envelope provided; seal the envelope and give it to

4) Please have your answers recorded, sealed and delivered by noon on Friday, October 8th; I will collect the forms from at that time.

Individual responses will be scored, showing where your perceptions do or do not match your test partner's. The purpose of this study is to develop a tool which can be used to help people improve their on-the-job communication. A general sumary will be sent to you when this research is complete.

Thank you for your time, thought and effort; your responses are the essence of this study.

Sincerely,

Betsy Crist

PSU Graduate Student

Encl: $\quad 1$ Supervisor-Subordinate Interpersonal Perception Method, 1 computer answer form, 1 Personal Inventory, and 1 Informed Consent. 


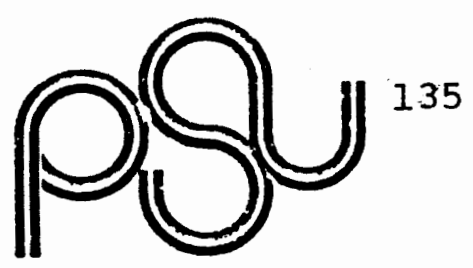

INSTRUCTION LETTER TO SUPERIORS:

FINAL STUDY

October 4, 1982

:iATI

IVI Hi:ily

(1) 1 (2) $1 ! 1$

ind. wre?tum

प्र/20/

$229-35,31$

college of and letters parlemernt of inumication

Dear Participant:

The Superyisor-Subordinate Interpersonal Perception Method (SSIPM) is designed to measure the accuracy or inaccuracy of your own and your co-worker's perceptions on a key range of issues related to your working relationship. The test is taken individually, and all responses will be confidential; code numbers will serve to keep appropriate information together.

You are asked to respond to the statements on the questionnaire in the context of your work environment, and on the basis of your work relationship with your test partner. Each statement should be thought of in a general sense; as you would judge things on the whole. For example, "he does his best" may remind you of a recent incident where you did not feel that your co-worker really did his best. If this was not his usual practice, and he generally does his best, please respond by affirming that he does his best, and disregard the unusual event.

You are being asked to respond to each statement from three perspectives: your own, what you think your co-worker feels, and what you think that he thinks that you feel. It may seem difficult to you, but people do think this way although often not consciously or continuously. I am asking you to think in this manner.

Please read each statement as a full sentence, for example, "I feel he does his best," - think of it as it applies to you and your test partner generally, and respond by filling in the appropriate spot on your computer page. Move through the questionnaire as quickly as possible, marking your first impression response.

DIRECTIONS FOR SCORING THE SUPERVISOR-SUBORDINATE INTERPERSONAL PERCEPTION METHOD:

1) Please do not discuss this test with your test partner until after both of you have finished testing.

2) Please do not write on the computer form except when shading in the answer spaces. 
3) Use a \#2 pencil and press hard, completely filling in the rectangular space provided for responses on the computer form.

4) Please respond to each statement; unanswered statements make it impossible to interpret all the following items.

51 Please note that there is a computer answer form which has elongated boxes numbered 1-24 horizontally. There are 18 test items, and ech item has 12 statements to which you should respond. Shade " $y$ " for yes, or " $n$ " for no, going verticcally from letter $A$ to $L$ on the computer answer form.

GENERAL INSTRUCTIONS:

1) Please read and sign the informed consent form.

2) Supervisors: please complete the performance appraisale form prior to doing the supervisor-Subordinate Interpersonal Perception Method.

3) After responding to the SSIPM, please complete the Personal Data Inventory.

4) Please enclose the computer answer pagee, the informed consent form, and the personal data form in the envelope provided. Seal the envelope, remove your name label from the envelope, and give it to the person whose name is on the envelope.

5) Please have your answers recorded, sealed, and delivered by noon on Friday, October 8th; I will collect the forms from at that time.

Individual responses will be scored, showing where your perceptions do or do not match your test partner's. The purpose of this study is to develop a tool which can be used to help people improve their on-the-job communication. A general summary will be sent to you when this research is completed.

Thank you for your time, thought and effort; your responses are the essence of this study.

Sincerely,

Betsy Crist

PSU Graduate Student 
Encl: $\quad 1$ Supervisor Subordinate Interpersonal Perception Method, 1 computer answer form, 1 Performance Appraisal, I Personal Data Inventory and I Informed Consent. 


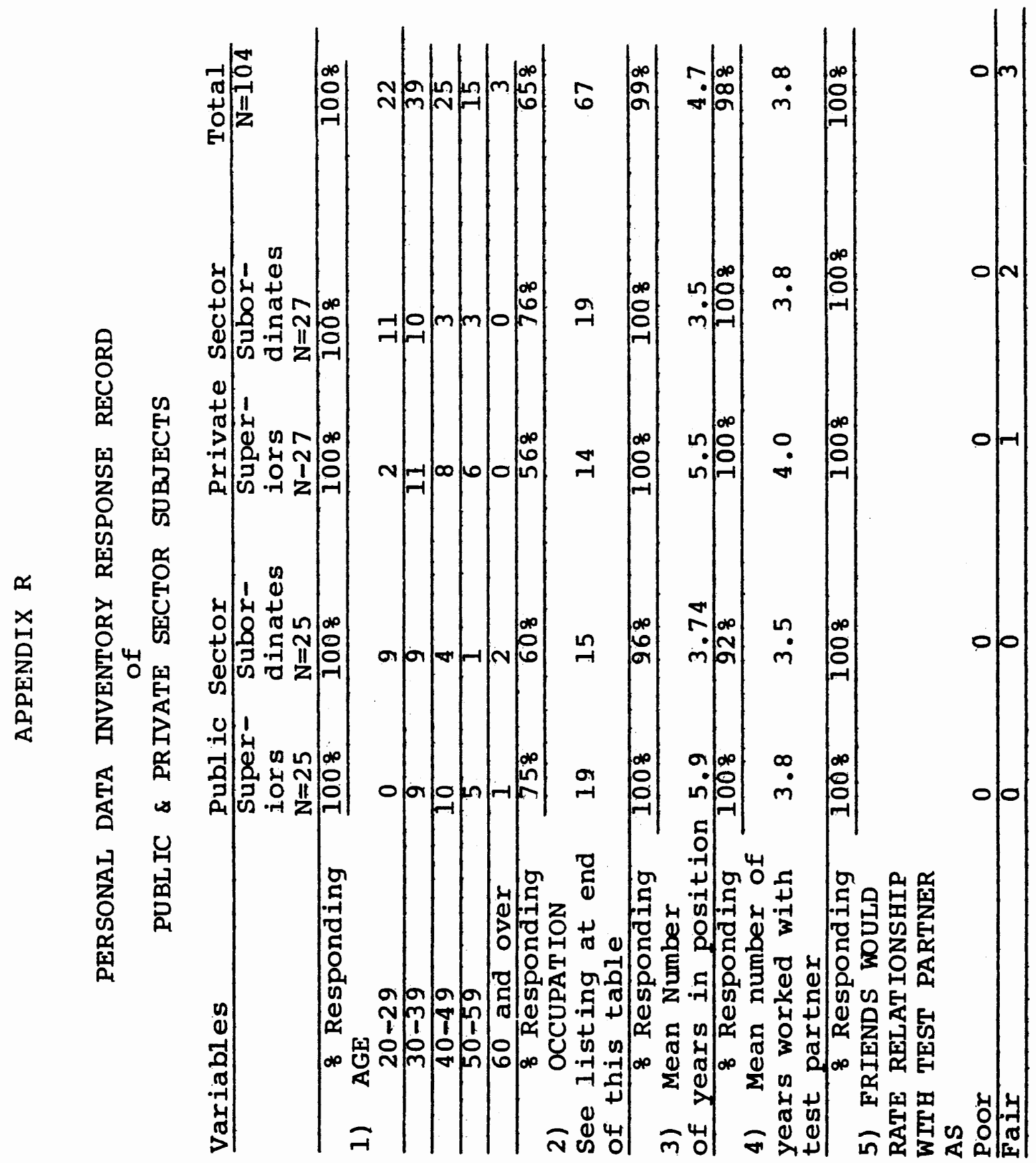




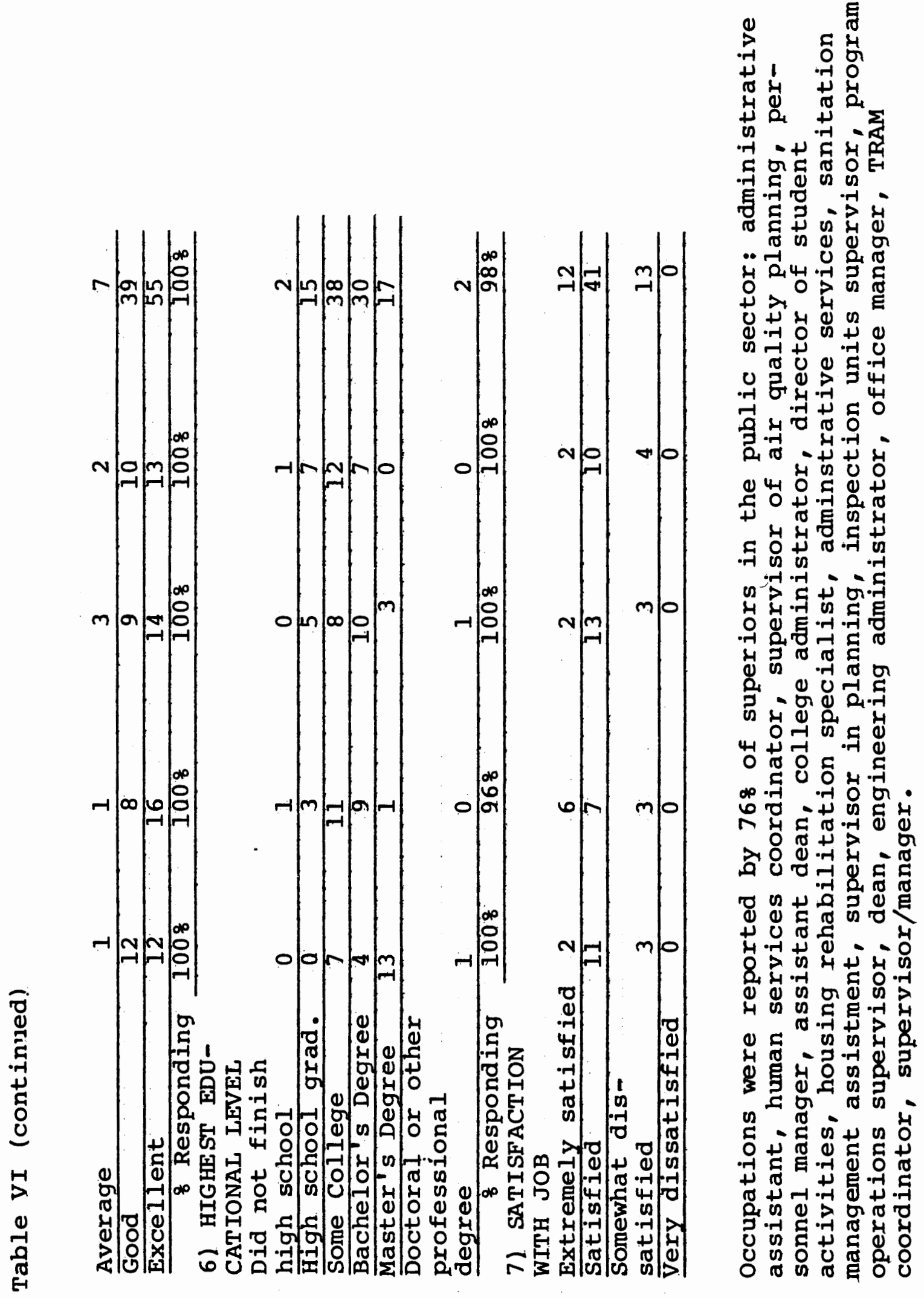




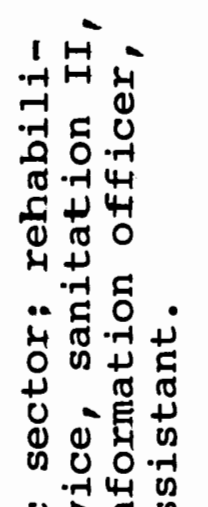

० म्न

$\rightarrow 0$

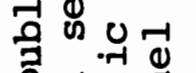

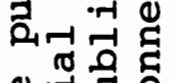

过

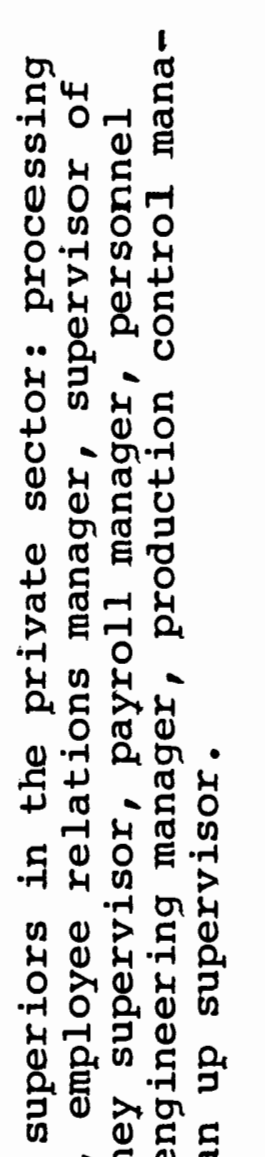

(1)

¿ั

군

0 б

$0+10$

क 5

ن

t

त) थ क्ष

मैन म्न

0 0 ว

岂声要

$\div$ ?

जु 0 त

द व मे का 40

밍

药羊

(1)

$+\rightarrow$ in

西些

- $\rightarrow 00$

ठठ

पूर 0 ठ

है न

苗

4

oㄴ 4

㑒 400

40 近

० 겅 엄

०

(1)

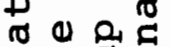

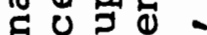

.

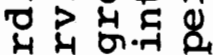

0 o 0

争 的 ह

जम 0 U

\&

出

可

0 व

ه

0 or

ล

1

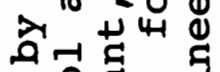

0 \% .7

$\nabla$ o 80

d.

r

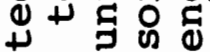

प्रे क्षे

○ 0 뭉

\& 0 ठ

ब 4 ते

তู

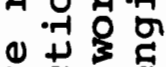

40 مू

0. क्ष क्ष

ग

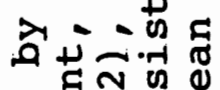

焉

$+\boldsymbol{E}$

मे 寻

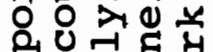

ब 0 ช

4 田 07

$\rightarrow 0$

(1) दे .न ते

0.

उ

的严

⿷匚⿱ 口)

$3 \notin>C \omega$

م. 둘

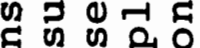

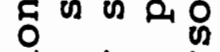

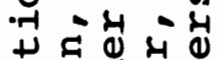

0)

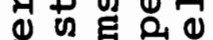

3 각교

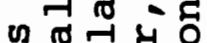

至 000

$\stackrel{H}{>}$ H

ส

동항

요 क्

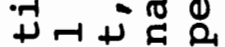

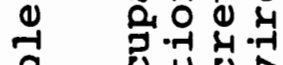

$0+0 ?$

व

ठํㅓㅇ 至

\% 0 on

임 구요

o 10

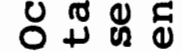

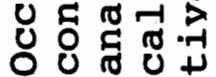


TOTAL PERSONAL DATA INVEINTORY RESPONSES FOR

SUPERIORS AND SUBORDINATES

Variable Superiors Subordinates

1) $\mathrm{AGE}$ 20-29

$30-39$

$40-49$

$50-59$

$60+$

$\begin{array}{cr}\mathrm{N}=52 & \mathrm{~N}=52 \\ 48 & 388 \\ 38 \% & 378 \\ 358 & 138 \\ 218 & 8 \% \\ 18 & 4 \%\end{array}$

Mean Age: Mean Age:

$40-49$ $30-39$

\section{2)}

NUMBER OF YEARS IN

POS IT ION

3)

Mean: 5.7

Mean: 3.6

NUMBER OF YEARS WORKED

WITH TEST PARTNER

4)

FRIENDS WHO KNOW WOULD

RATE RELATIONSHIP WITH

TEST PARTNER AS

Mean: 3.9

Mean: 3.7

Poor

Fair

Average

Good

Excellent

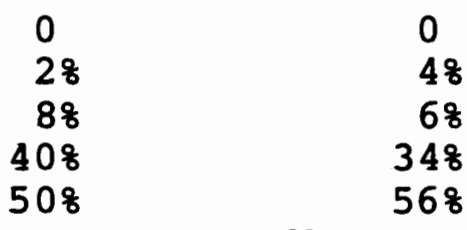

Mean:

Excellent \&

Good
48

$6 \%$

348

568
5)

HIGHEST EDUCATIONAL

LEVEL

Did not finish high school

High school graduate

Some college

Bachelor's degree

Master's degree

Doctoral or other pro-

fessional degree
0

98

298

278

318

48

Mean Range:

Bachelor's Degree
Mean :

Excellent

6)

SATISFACTION WITH JOB

Extremely satisfied

88

168 
Superiors

Very satisfied

Satisfied

Somewhat dissatisfied

Very dissatisfied
$46 \%$

35 웅

118

0
Subordinates

338

37 응

$14 \%$

0

ange :

Satisfied 